\title{
WestVirginiaUniversity
}

THE RESEARCH REPOSITORY @ WVU

Graduate Theses, Dissertations, and Problem Reports

2007

\section{Carbon promoted water electrolysis to produce hydrogen at room temperature}

Sukanya Ranganathan

West Virginia University

Follow this and additional works at: https://researchrepository.wvu.edu/etd

\section{Recommended Citation}

Ranganathan, Sukanya, "Carbon promoted water electrolysis to produce hydrogen at room temperature" (2007). Graduate Theses, Dissertations, and Problem Reports. 1837.

https://researchrepository.wvu.edu/etd/1837

This Thesis is protected by copyright and/or related rights. It has been brought to you by the The Research Repository @ WVU with permission from the rights-holder(s). You are free to use this Thesis in any way that is permitted by the copyright and related rights legislation that applies to your use. For other uses you must obtain permission from the rights-holder(s) directly, unless additional rights are indicated by a Creative Commons license in the record and/ or on the work itself. This Thesis has been accepted for inclusion in WVU Graduate Theses, Dissertations, and Problem Reports collection by an authorized administrator of The Research Repository @ WVU. For more information, please contact researchrepository@mail.wvu.edu. 


\title{
CARBON PROMOTED WATER ELECTROLYSIS TO PRODUCE HYDROGEN AT ROOM TEMPERATURE
}

\author{
by \\ Sukanya Ranganathan \\ Thesis submitted to the \\ College of Engineering and Mineral Resources \\ at West Virginia University \\ in partial fulfillment of the requirements \\ for the degree of \\ Master of Science \\ in \\ Electrical Engineering
}

Approved by

Dimitris Korakakis, PhD., Chair

Mohindar.S.Seehra, PhD., Co-chair

Ayyakkannu Manivannan, PhD.

Lawrence Hornak, PhD.

Mark.A.Jerabek, PhD.

Lane Department of Computer Science and Electrical Engineering

Morgantown, West Virginia

2007

Keywords: electrolysis, electrochemistry, hydrogen production, energyefficiency

Copyright 2007 Sukanya Ranganathan 


\section{ABSTRACT}

\section{CARBON PROMOTED WATER ELECTROLYSIS TO PRODUCE HYDROGEN AT ROOM TEMPERATURE}

\section{by Sukanya Ranganathan}

The objective of the work was to conduct water electrolysis at room temperature with reduced energy costs for hydrogen production. The electrochemical gasification of carbons consumes only $9.6 \mathrm{kcal} / \mathrm{mol} \mathrm{H}_{2} \mathrm{O}$ compared to $56.7 \mathrm{kcal} / \mathrm{molH}_{2} \mathrm{O}$ for conventional water electrolysis. In this work, carbon-assisted hydrogen production and the reaction energetics/kinetics at applied potentials $\left|E^{0}\right|$ between 0.1 and $1.8 \mathrm{~V}$ are studied. The carbon promoted water electrolysis could be performed at applied potentials as low as $\left|E^{0}\right|=0.21 \mathrm{~V}$ as opposed to conventional water electrolysis which requires $\left|E^{0}\right|>1.25 \mathrm{~V}$. The study reveals that the $\mathrm{H}_{2}$ produced per $\mathrm{W} \mathrm{h}$ is higher at the lower voltages, but longer times are required to produce the same amount of $\mathrm{H}_{2}$. The following parameters were considered for evaluating the process: time taken, potential applied, current required and amount of carbon to be added. Based on such an evaluation, practical parameters of $\left|E^{0}\right| \simeq 0.5 \mathrm{~V}$ and carbon concentration $\left(0.08 \mathrm{~g} / \mathrm{cm}^{3}\right)$ are suggested. 


\section{DISCLAIMER}

This report was prepared as an account of work sponsored by an agency of the United States Government. Neither the United States Government nor any agency thereof, nor any of their employees, make any warranty, express or implied, nor assume any legal liability or responsibility for the accuracy, completeness or usefulness of any information apparatus, product, process disclosed, or represents that its use would not infringe privately owned rights. Reference herein to any specific commercial product, process, or service by trade name, trademark or manufacturer, or otherwise does not necessarily constitute or imply endorsement, recommendation, or favoring by the United States Government or any agency thereof. The views and opinions of authors expressed does not necessarily state or reflect those of the United States Government or agency thereof. 


\section{ACKNOWLEDGEMENT}

The chapter of my thesis which I write with utmost pleasure, for now, I have the opportunity to express my gratitude to all of them who have guided and accompanied me throughout this journey. It is a pleasant aspect to unveil the 'silent gratitude' which I have kept to myself for all these years.

First and foremost I would like to express my deepest thanks to my family. I thank you mom and dad for believing in me and giving me the freedom to pursue my dream. All my achievements are always embedded with your encouragement, constant support and love. I really appreciate you both for being with me the 24 years of my life. I will always do my best to make you proud of me. I would also like to thank my brother Prabhu for being a perfect brother. His constant encouragement throughout my Masters and timely suggestions helped me greatly.

Dr.Mohindar Seehra, thank you for guiding me throughout this research. Your enthusiasm in research and tenacity to perfection continues to amaze me. You have really been patient in correcting my numerous errors experimentally as well as in writing. Thanks for all your efforts in making me learn the perfect way of research. Besides being an excellent advisor, thanks for all your support and care especially during my parents visit.

I would like to thank Dr.Manivannan for providing me advice on the work on a day-today basis during the initial stages of this project. Also thanks Dr.Manivannan for being available whenever needed throughout this work. I would also like to thank his wife, 
Shanthi Manivannan and his kids for wonderful get-togethers. He and his family have always welcomed me as a student and friend to their home.

Also thanks to Dr.Korakakis, Dr.Hornak and Dr. Jerabek for their time and significant contribution to the betterment of my work. Dr.Jerabek, thanks for your valuable comments on my thesis. Also I have really enjoyed and benefited greatly out of their courses.

I would like to thank my friends Latha, Niveditha, Renee, Kedhar, Senthil \& Balaji who provided me a home-like stay during my initial days in Morgantown. I am indebted to Latha, for guiding me in the initial stages of my work in the Physics department. Special thanks to Aashish for his company in the lab and for cheering me always. I wish to thank Kedhar for his valuable suggestions in every aspect. Also I thank Santhosh Hooli for helping me in my courses.

I am really grateful for having known this exceptional friend Arvind during my stay in Morgantown. Thanks for all your encouragement and your valuable comments on my work.

Thanks Karthik for all the fun times and for regularizing my workout schedule. I feel both are missing after you left. Hari, Deepti, Dilip, Abishek, Mahitha \& Avinash thank you all for making my life more enjoyable in the US. Thanks Hema for being a great roommate and a friend.

Thanks to all colleagues in my lab especially Prasanth, Susmita, Shilpa and Vivek for providing me with such a friendly atmosphere. Susmita, I thank you for all your wonderful food and innumerable guidance. Thanks Shilpa for helping me with corrections in this work. 
I would like to thank my friends in India especially Sathya, Ramya, Lavanya. K.P, S.R.Karthik, Swathi, Saira,Shanmuga Priya, Sunil, Manoj and Prakash for their continued support since my undergraduate years.

Last but not the least financial support provided by the U.S. Department of Energy (contract DEFC26- 05NT42456) through Consortium for Fossil Fuel Science is gratefully acknowledged. 


\section{DEDICATION}

I would like to dedicate this work to my family, who have been a source of constant support and encouragement. I would also like to dedicate this work to all my teachers throughout my entire life, who have made it possible for me to pursue this degree. Their lessons will remain forever in making me a responsible individual. 


\section{TABLE OF CONTENTS}

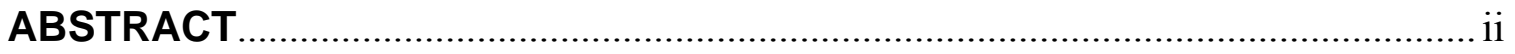

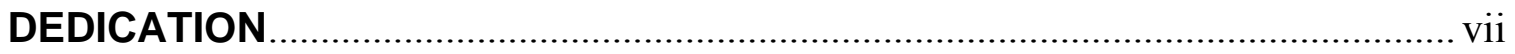

TABLE OF CONTENTS …......................................................................................... vii

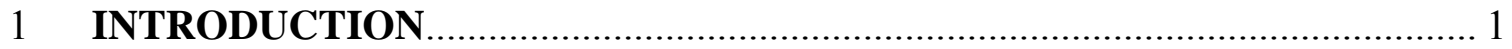

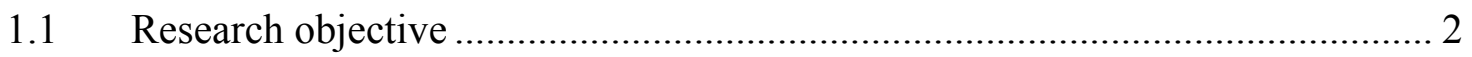

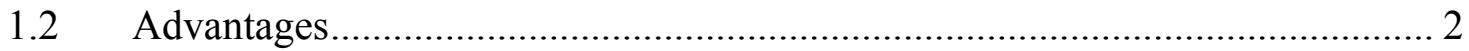

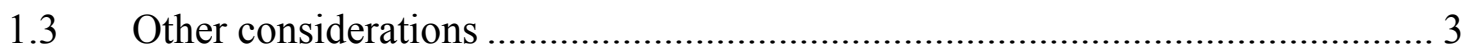

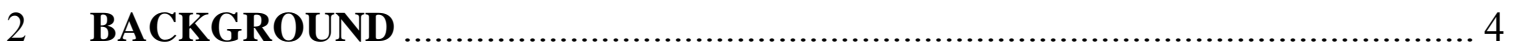

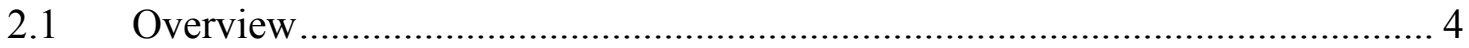

2.2 Major techniques for hydrogen production.................................................... 4

2.2.1 Hydrogen production from fossil fuels ................................................... 4

2.2.2 Hydrogen production by electrolysis ....................................................... 7

2.2.3 Hydrogen production from thermochemical processes ............................ 11

2.2.4 Hydrogen production from other processes ........................................... 15

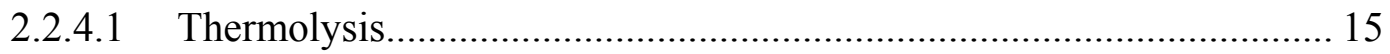

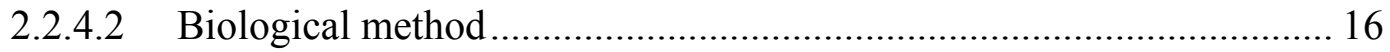

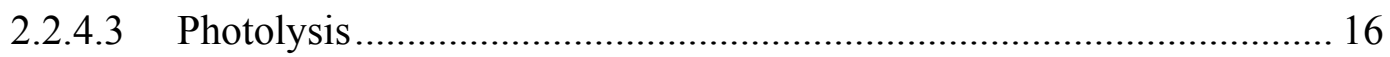

2.3 Electrochemical gasification of coal............................................................. 17

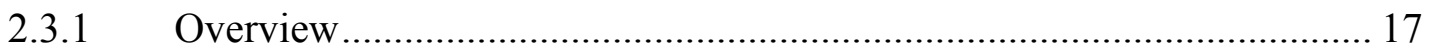

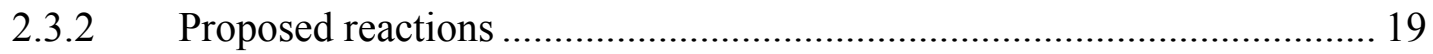

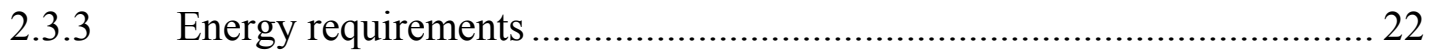




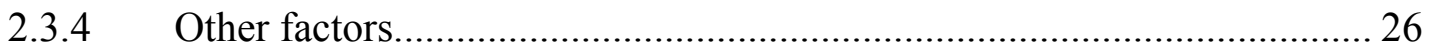

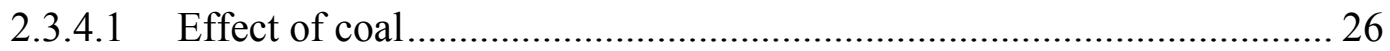

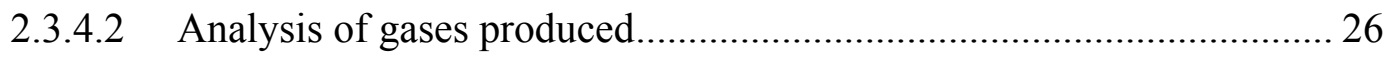

2.3.4.3 Effect of potential and activation energy .............................................. 27

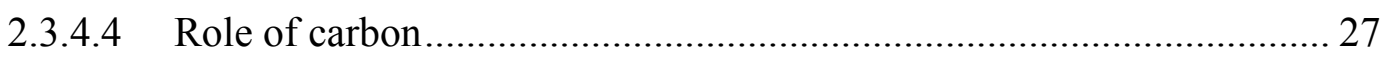

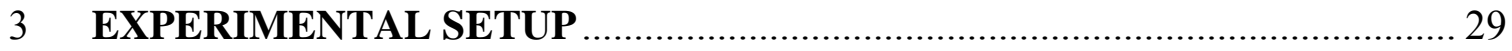

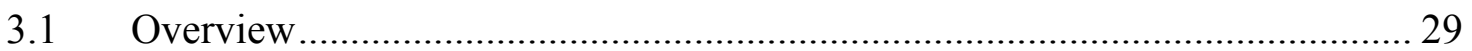

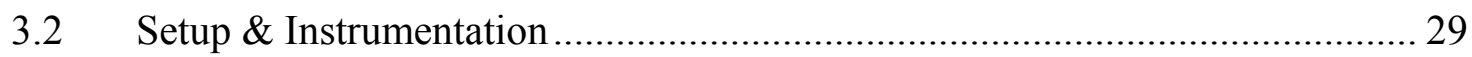

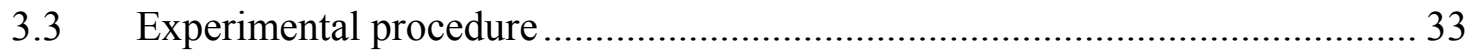

3.4 Electrode Electrolyte and other considerations............................................. 34

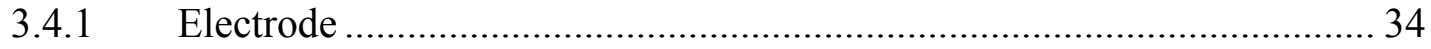

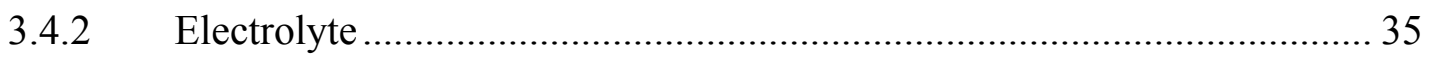

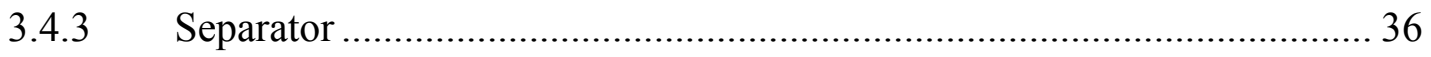

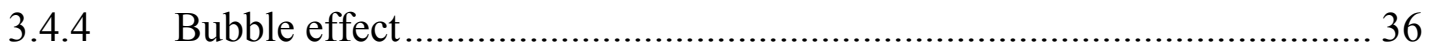

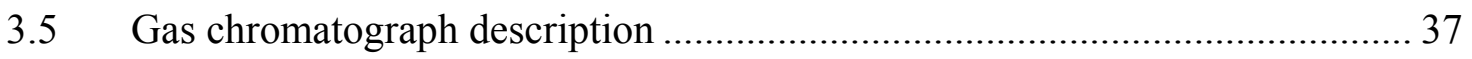

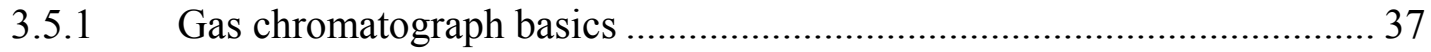

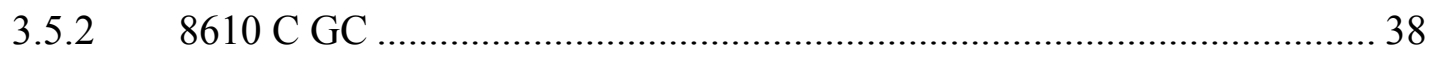

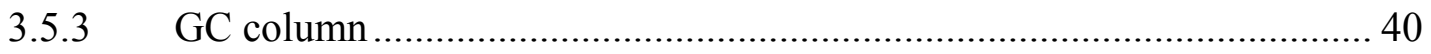

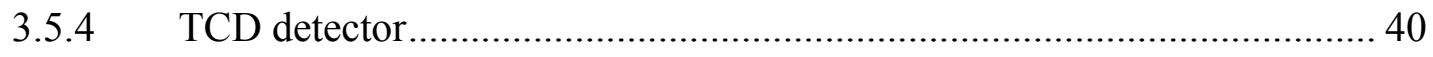

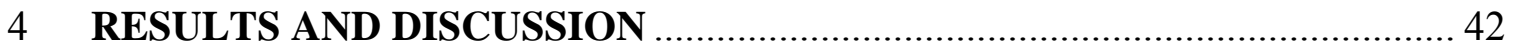

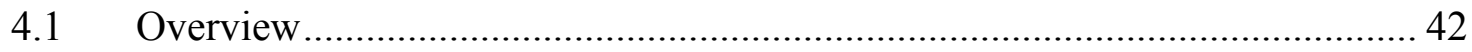

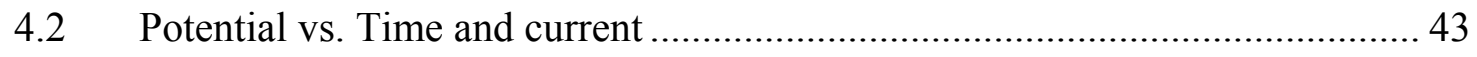

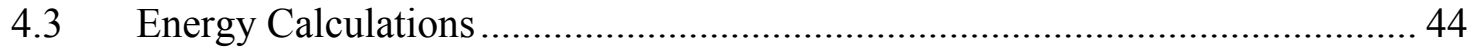


4.4 Amount of hydrogen produced ............................................................... 45

4.5 Influence of current on hydrogen produced ............................................... 46

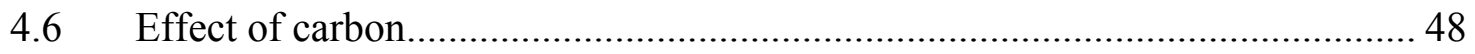

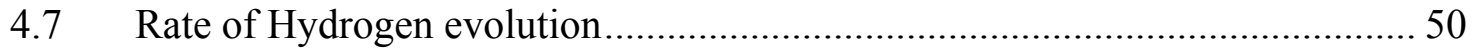

5 CONCLUSIONS AND FUTURE WORK .................................................. 51

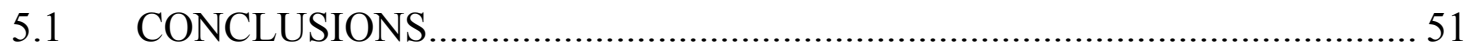

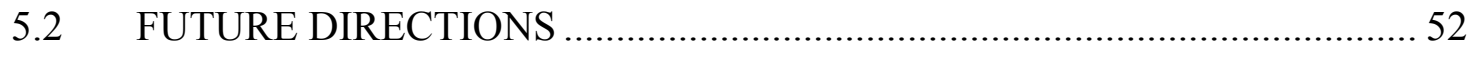

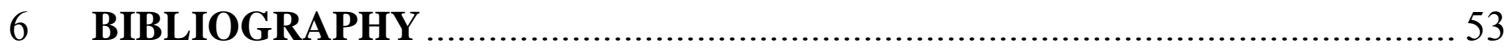




\section{LIST OF FIGURES}

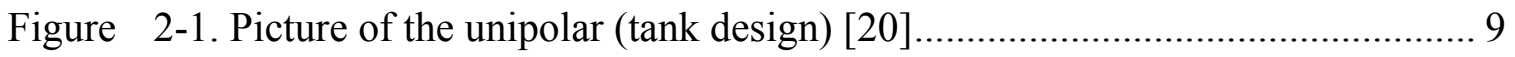

Figure 3-1.Schematic of the three-electrode cell used in the experiments. The surface area of the Pt anode (cathode) is $6.8 \mathrm{~cm}^{2}\left(2.5 \mathrm{~cm}^{2}\right)$. The contents of the anode compartment were constantly stirred by a magnetic stirrer (not shown) [1] .......... 30

Figure 3-2.Electrodes and Electrochemical cell used ........................................... 31

Figure $3-3$. Electrochemical setup along with potentiostat ................................... 32

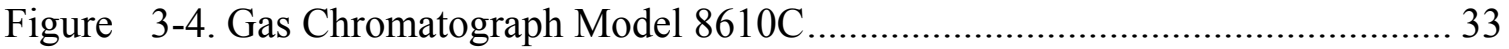

Figure 3-5.Presence of bubbles at the electrode. From macroscopic vertical electrode to

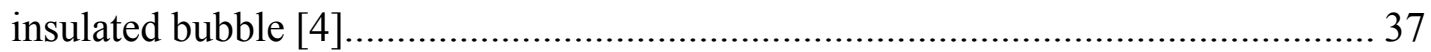

Figure 3-6.Schematic and working of Multi Gas analyzer 8610 C GC [60]................ 39

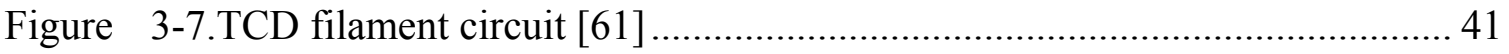

Figure 4-1.Time $t_{H}$ needed to produce the same amount of $\mathrm{H}_{2}$ and the current in the circuit are plotted against the applied potential $E^{0}$ vs SHE for run 2.

Figure 4-2. Quantity $A_{H}$ representing the amount of hydrogen produced per W-hr of energy consumed is plotted against potential $E^{0}$

Figure $4-3 . \mathrm{H}_{2}$ produced per minute for run2 is plotted against the current $I_{0}(\mathrm{~mA}) \ldots . .47$

Figure 4-4.Variation of the quantity $A_{H}\left(\mathrm{H}_{2}\right.$ produced per W-hr) is plotted against the carbon concentration for three operating potentials $E^{0}$. 48

Figure 4 -5.Power (watts) and time $t_{H}$ (min) vs. carbon concentration at $E^{0}=0.68 \mathrm{~V} \ldots .49$

Figure $4-6$. Power (watts) and time $t_{H}(\mathrm{~min})$ vs. carbon concentration at $E^{0}=1.4 \mathrm{~V} \ldots \ldots .49$

Figure 4-7. Evolution rate $\left(1 / t_{H}\right)$ and current $(\mathrm{mA})$ vs. Potential $\left(E^{0}\right) \ldots \ldots \ldots \ldots \ldots \ldots \ldots \ldots . . . . . . . . . . . . .50$ 


\section{니ST OF TABLE}

Table 4-1.Measured and computed quantities for selected $E^{0}$ values with $\left(0.08 \mathrm{~g} / \mathrm{cm}^{3}\right)$

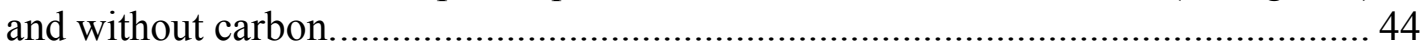




\section{INTRODUCTION}

Energy has always been the primary focus of mankind and it continues to drive the economy through a series of technological advances. The energy-based industrial and scientific revolution, places a demand on researchers and industries to produce sustainable energy technologies. Conversion of chemical energy stored in fossil fuels or in nuclear processes has been the major contributor for the world's energy demand. Fossil fuel technology dates back to the industrial revolution of $19^{\text {th }}$ century and it continues to be the leading supplier for energy consumption even today. However the combustion of fossil fuels spews out toxic substances like COx, NOx, SOx etc, into the air. Energy sources such as sun, wind or other renewable sources can be considered as future alternatives. However the lack of commercial plants makes them a long term possibility. Hence in the intermediate period a solution which utilizes the currently available plants with minor changes and that would minimize emissions is highly desired. Hydrogen plays a key role as an energy storage media and it can be generated by various techniques. Hydrogen production via water electrolysis is still considered to be the low cost alternative if energy efficient techniques are established. The main advantage of electrolysis is production of very pure hydrogen unlike other processes. The other major reasons for considering water electrolysis advantageous are: it requires no moving parts, requires little space, and is non-polluting. The research conducted by National Renewable Energy Laboratory (NREL) claims that about $58 \%$ of the cost factor in electrolysis is electricity [1]. The electricity cost which contributes to the cost of electrolytic hydrogen production needs to be reduced to make the process competitive. Hence in an effort to 
address this issue a model proposed in the literature was considered and tested experimentally, the details of which are presented in the following chapters.

\subsection{Research objective}

This research on a broader perspective is focused on hydrogen production at an acceptable cost for a hydrogen based economy. The electrochemical process proposed by Coughlin and Farooque utilizes coal assisted water electrolysis to achieve energy reduction [2]. The energy costs would be reduced by a factor of 6 if the proposed reaction proved to be true. The model though proposed was not actually tested at low enough voltages in terms of amount of hydrogen produced. Hence the specific focus of the current work was to test the usefulness of the model proposed by Coughlin and Farooque. The initial work was carried out with activated carbon to reduce the complexities involved with impurities in coal. It aimed at testing a wide range of operating potentials from $0.1 \mathrm{~V}$ to $1.8 \mathrm{~V}$ and measure the relative amount of hydrogen produced rather than just the oxidation rate measured in the earlier work [2].

\subsection{Advantages}

The proposed process, unlike the hydrogasification of coal, does not have complex gaseous products such as tars, ash and sulfur compounds. Also in such processes, the hydrogen and carbon monoxide contents need to be adjusted by means of water-gas shift reactions. The process chemistry of coal gasification reaction takes place at high temperatures (around $1000^{\circ} \mathrm{C}$ ). However the proposed process of electrochemical gasification using carbons takes place at mild temperatures, even at room temperature. 


\subsection{Other considerations}

The anode compartment produces pure gas streams of carbon oxides. However, since carbon is used only as a reagent the amount produced is considerably smaller compared to coal gasification processes. Also the carbon dioxide concentration produced can be lowered by considering alternative electrode materials [3]. Other catalysts along with carbon can also lead to reduced amount of carbon dioxide production. Carbon sequestration is an effort to lock up $\mathrm{CO}_{2}$ (for example in large underground formations) so it cannot enter the earth's atmosphere. Such efforts can also be considered for concerns regarding $\mathrm{CO}_{2}$ emissions. With such efforts economic estimates for those processes along with hydrogen production costs need to be made. Since this work is only an initial effort to investigate a proposed process, the above considerations are left for future work. 


\section{BACKGROUND}

\subsection{Overview}

This chapter provides an insight into various techniques used for hydrogen production in the industry. The following techniques namely production from fossil fuels and electrolysis are well established and there are various thermochemical water decomposition processes in development. In each of these methods of hydrogen production, advantages and disadvantages and factors affecting costs are reviewed in detail [4]. Other techniques such as bio photolysis, solar energy conversion of water to hydrogen and some of the emerging techniques of hydrogen production are listed. The electrochemical gasification of coal, which inspired our current research, is also discussed in detail [2].

\subsection{Major techniques for hydrogen production}

\subsubsection{Hydrogen production from fossil fuels}

There are several methods to produce hydrogen from fossil fuels. The major processes include catalytic decomposition of methane, steam-iron process, steam reforming and catalytic \& non-catalytic partial oxidation reaction $[5,6]$. The basis for catalytic decomposition of methane is that under certain conditions of temperature and pressure and in the presence of a catalyst, methane can be converted to carbon and hydrogen. The reaction is highly endothermic and heat must be supplied to sustain the temperature. The most basic process consists of a fluidized bed reactor which contains a 7\% nickel on

alumina catalyst and a fluidized bed regenerator [5]. Then a sulfur free natural gas is passed through the catalyzed bed so that fluidization occurs in the reactor. As the natural 
gas moves upward, the hydrogen is released and the carbon is deposited on the catalyst surface. The catalyst needs to be continuously removed and regenerated. Various researches are underway to replace the catalyst and one such catalyst is carbon nanofibers [7].

In the steam-iron process, crushed and dried coal is reacted with steam and air to make producer gas. The producer gas is then used to reduce the oxidized iron from the steamiron reactor [8]. The process involves various steps broadly classified as: coal storage and preparation, producer gas generation \& steam iron reactor, upgrading the oxidizer effluent to the desired hydrogen product and power generation from reducer off-gas using a combined power cycle. The process has attracted considerable attention since it does not require subsequent shifting and $\mathrm{CO}_{2}$ removal steps. Applying fluidized beds to the conventional steam-iron process enables a continuous steam-iron process [9]. The total plant cost is comparatively reduced in a continuous steam-iron process [10].

Catalytic steam reforming of hydrocarbons aims at converting much of the steam and hydrocarbon as possible into a mixture of $\mathrm{CO}$ and $\mathrm{H}_{2}$. The $\mathrm{CO}$ produced in the reaction is converted into $\mathrm{CO}_{2}$ and more $\mathrm{H}_{2}$ in a subsequent water-gas shift step. The catalytic steam reforming process can be enhanced by optimizing the temperature and pressure conditions on the chemical equilibrium. The optimum conditions at which the maximum $\mathrm{H}_{2}+\mathrm{CO}$ mole fraction is reached, are at $1600^{\circ} \mathrm{F}, 14.7 \mathrm{psig}$, with a steam-to-hydrocarbon ratio of 2.0 [11]. Catalyst selectivity is important in steam reforming of hydrocarbons since some catalysts promote the formation of methane rather than hydrogen and carbon monoxide. The development of catalysts which resist carbon deposition continues to be 
an area of research [12]. Nickel oxide catalysts with supports of corundum or alumina/ calcium aluminate are considered to be robust in recent researches [13].

In catalytic partial oxidation reaction, the heat required for the reaction is generated directly in the reaction vessel, unlike other processes wherein an external heat source is used. The heat required for the reaction is supplied directly by mixing both oxygen and steam with the hydrocarbon. The steam reacts with the hydrocarbon in a reaction similar to steam reforming and the oxygen reacts with remaining hydrocarbon to form $\mathrm{CO}$ and $\mathrm{CO}_{2}$. The oxidation reaction supplies the heat required by the reforming reactions. The low temperature $\left(1500\right.$ to $\left.1700^{\circ} \mathrm{F}\right)$ partial oxidation reactions require a catalyst, hence the name catalytic partial oxidation. At high temperatures $\left(2000\right.$ to $\left.2500^{\circ} \mathrm{F}\right)$ the reaction takes place without catalyst. On studying the temperature and pressure effects it is observed that the oxygen-to-hydrocarbon ratio decreases with increasing pressure and decreasing temperature whereas the steam-to-hydrocarbon ratio shows the exact opposite trend. The use of a catalyst to enhance the reaction rates in a partial oxidizer has been patented and commercialized [14].

A high rate of partial oxidation can be achieved at a high temperature without a catalyst. The limitations like reduced availability and sharp increase in price of natural gas and naphtha and need to produce hydrogen at high pressure make non-catalytic partial oxidation the only solution. In non catalytic partial oxidation, any hydrocarbon from methane to a high-ash, high-sulfur coal can be reacted with steam and oxygen at pressures up to the metallurgical limits of the reactor. However since more oxygen is needed, more $\mathrm{CO}$ must be shifted. Also removal of sulfur as well as $\mathrm{CO}_{2}$ is required in the 
gas cleanup system. Various commercial processes based on different technologies developed by Texaco, shell and Montecatini exist [15]. The optimization of the process involves examining the experimental conditions over a wide range of temperatures and mixture compositions [16].

Steam-iron process and catalytic decomposition are preferred if high-purity hydrogen is to be produced directly. A subsequent water-gas shift reaction is required in the rest of the three methods to separate hydrogen from its product, the product being synthetic gas containing carbon monoxide. Although the catalytic decomposition of methane is simpler in terms of eliminating shift conversion and $\mathrm{CO}_{2}$ removal, the fluidized beds and solid circulation systems needed for the reaction are expensive and hence the process is preferred in only small installations. Steam reforming and partial oxidation reaction both produces a synthetic gas rather than high-purity hydrogen. The hydrogen content of this gas must be increased by shifting the $\mathrm{CO}$ and subsequently removing the $\mathrm{CO}_{2}$. Catalytic oxidation has the limitations of both steam reforming and non-catalytic partial oxidation and few advantages of either process. However hydrogen production by steam reforming is less expensive and hence it is preferred over catalytic oxidation. Another fossil-based hydrogen production method that needs special mention is coal gasification process. It is explored in detail in later sections.

\subsubsection{Hydrogen production by electrolysis}

Electrolysis of water is carried out by passing a direct electric current between two electrodes placed in a conducting electrolyte. For water to decompose the applied voltage between the two electrodes must be greater than that corresponding to the free energy of formation of water plus the voltage needed to overcome electrode and ohmic 
polarizations [17]. The electrolysis cell in its most basic form is reliable and trouble free as it involves no moving parts and is also the most efficient way to generate hydrogen under pressure. The most important characteristic of electrolysis is that hydrogen and oxygen are separated at the same time from water. The cost of electrolysis mainly increases because of the electric generation step i.e. the power stations required to run the electrolyzers. There are two forms of current day water electrolysis, namely alkaline and polymer. Alkaline electrolysis is the most typical of water electrolyzers. There are two forms of alkaline technology: namely unipolar and bipolar [18]. Unipolar alkaline technology is the simplest electrochemical setup which has been used for many years (shown in figure.1). It has no moving parts associated with it, which makes it simpler to manufacture and repair. Two electrodes namely cathode and anode are immersed in an alkaline solution and separated from each other by a diaphragm. The diaphragm is usually a semi-permeable membrane that allows only salts to travel between the two ends and prevents the gases produced from mixing with each other. The $\mathrm{H}_{2}$ and $\mathrm{O}_{2}$ produced is collected and dried to make it free of water vapor. 


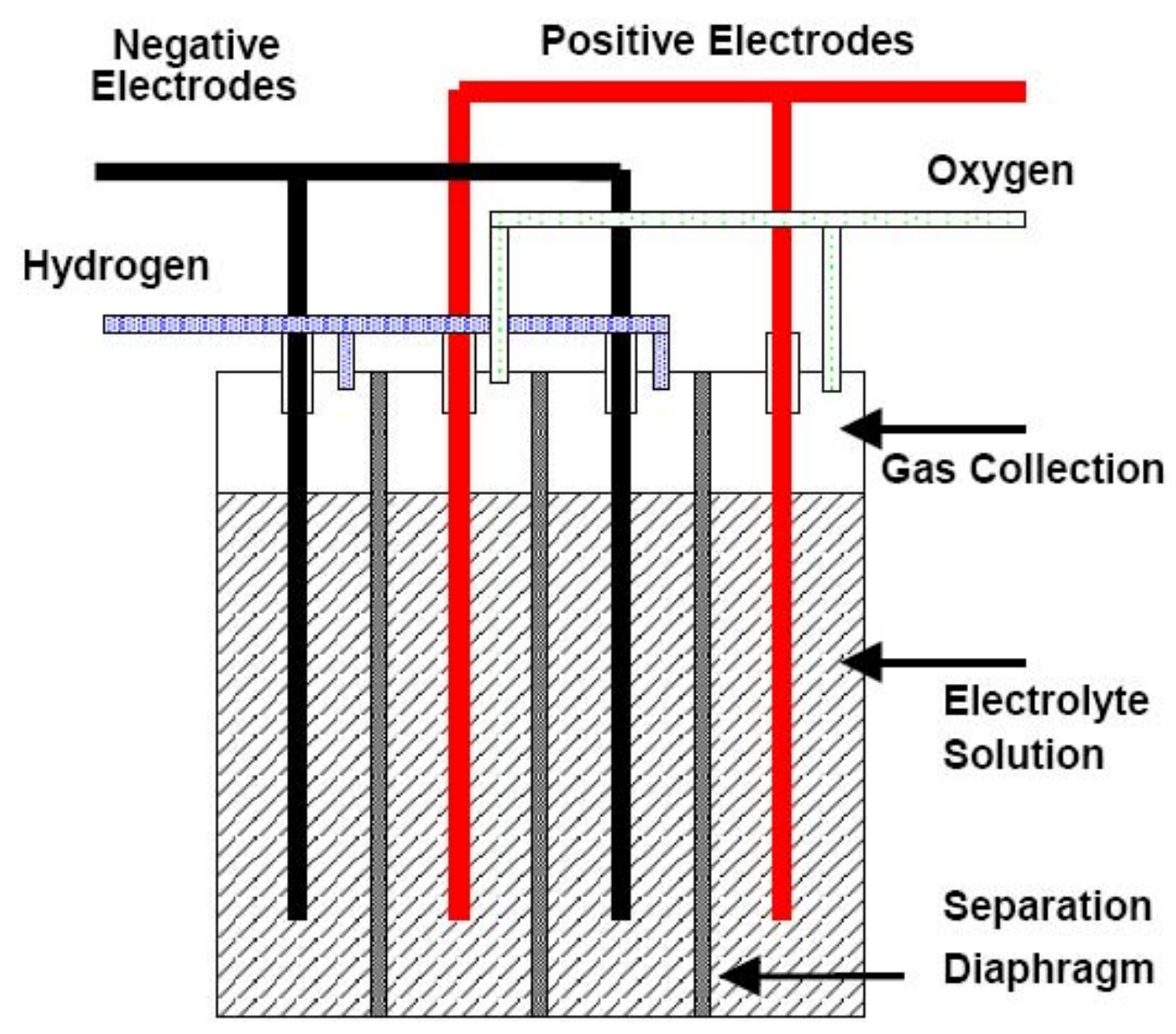

Figure 2-1. Picture of the unipolar (tank design) [20]

The disadvantage with the unipolar design is that operating current density and temperature are lower [19]. A unipolar setup is shown in the figure above $[19,20]$. On the other hand the bipolar electrolyzers use stacks in which the positive end of the previous electrode is connected to the negative of the next. The design for such an electrolyzer is given in Figure.2 [19, 20]. 


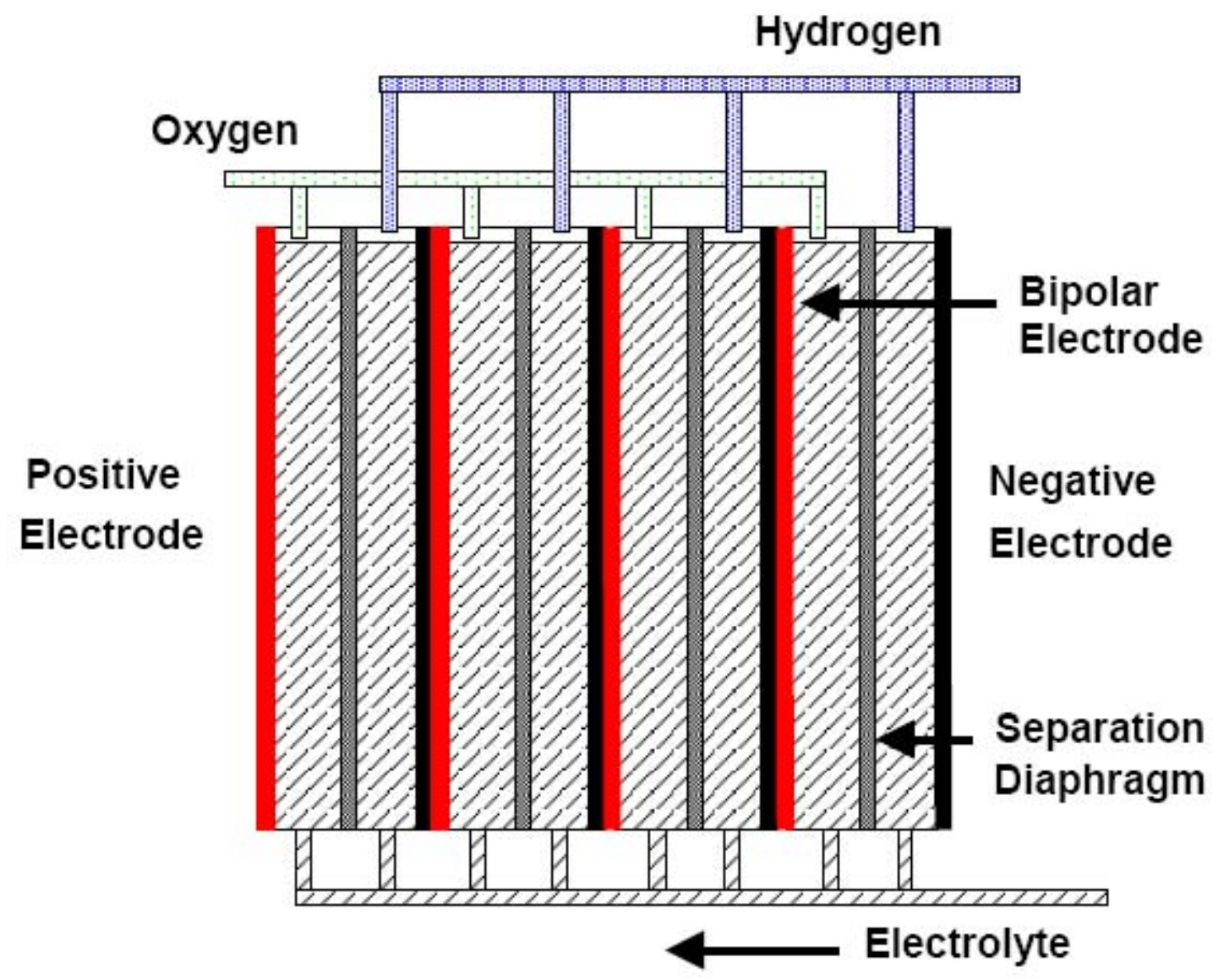

Figure 2-2. Picture of the bipolar (filter-press) design [20]

The design is called a bipolar design because each face acts as positive electrode for one cell and the opposite face as the negative electrode of the next cell. However in practice the electrodes are separated and the electrical connection is achieved through a solid metal separator plate. This aids in separating the hydrogen cavity of one cell from the oxygen cavity of the next. The advantage of such a design is less floor space, capability to operate at higher temperature and pressure [21]. The disadvantage is that the entire stack needs to be serviced in case of failure. [20]. 
Proton Exchange Membrane electrolysis (PEM) also known as Solid Polymer Electrolyte (SPE) technology is the other commercially available technology based on electrolysis [20]. It uses an ion-exchange resin instead of the electrolyte [22]. Usually the membrane is a Teflon-like substance attached with sulfonic acid groups [17]. This membrane aids to conduct water electrolysis as well as to separate the anode and cathode. To provide electric continuity, a metal separator is introduced between cells. Water is circulated through the cavity between metal separator and the electrode plate. A SPE cell is capable of very high current densities and is highly compact with fewer cells. The disadvantages of the SPE cell are that they are more expensive than their alkaline counterparts and the electrolyte is more corrosive which requires expensive metal components to be used in the cell. Water electrolysis cost using any of the above technology is mainly determined by the capital cost and the system operating cost. However this method is well established for the production of hydrogen and commercial electrolyzers are simple, reliable and efficient [17].

\subsubsection{Hydrogen production from thermochemical processes}

Thermochemical hydrogen-production has the potential for higher efficiency in converting thermal energy to hydrogen than water electrolysis [23]. Thermochemical hydrogen- production is a process in which water is material input and mainly thermal energy or heat as an energy input. The output of the process is hydrogen and oxygen and waste heat. The process involves a series of chemical reactions to reach water decomposition. The products from each reaction should be separated and either recycled or sent to the next reaction. The various "heats of reaction" are provided by the heat transferred to heat or cool the various reactant and product streams. Throughout the 
process, useful work or electricity is required for operating or pumping separation equipment or electrochemical reactions. The 'pure' thermochemical process is one which requires heat as energy input, whereas if an electrochemical step is included in the reaction it becomes a 'hybrid' process. The heat source to drive the reaction could be high-temperature, gas-cooled, nuclear reactor (HTGR) or a solar furnace [24-26].

Thermochemical processes are not yet fully developed processes. Hence most of them are in the conceptual research or development stages. The thermodynamics of closed cycle water splitting processes have been studied and feasibility of different processes has been established from an energy standpoint [27]. A single-step water decomposition process like electrolysis can be carried out at various temperatures. If the reaction is done at higher than room temperature, the work requirement at the higher temperature should be reduced relative to operation at lower temperatures. This means that the change in free energy or Gibbs function $(\Delta \mathrm{G})$ should decrease with increasing temperature. Also if a reaction has a positive entropy change, therefore, raising the operating temperature will reduce the work requirement by a like amount. In a two-stage process, two reaction processes can be found which requires no useful work input. The steam-methane reforming reaction is a two-stage process which almost satisfies the above reaction. This reaction requires very large entropy change and has been suggested as a "good" reaction for thermochemical processes, however the work of separation for this reaction is high. As shown by Funk and Reinstrom [29] and reiterated by Abraham and Schreiner [30], it is possible for a multistage process to satisfy the first and second laws of thermodynamics and with a constraint that no useful work be expended in the process. Such a situation can be visualized by considering a general thermochemical process comprising an arbitrary 
number of steps where each reaction exhibits some change in enthalpy $(\Delta \mathrm{H})$, entropy $(\Delta$

S) and Gibbs free energy $(\Delta \mathrm{G})$. The entire process becomes similar to an ideal electrolysis cell, if the entire process is operated reversibly at $25^{\circ} \mathrm{C}$ at $1 \mathrm{~atm}$ since the work and heat requirement are the same for all reversible processes. The work requirement in electrolysis can be reduced by operating at higher temperatures; however by choosing the operating temperatures in the thermochemical process properly, it is possible to reduce the useful work requirement to zero at least theoretically. The main work requirement in such a process is the work of separation required in various reaction steps. The unreacted materials need to be recycled and the flow rates must be set to achieve the overall stoichiometry of the chemical reaction. The work of separation can be theoretically calculated pressure, gibbs free energy change etc. However the actual energy requirements vary considerably from theoretical estimates. A complete evaluation of the thermochemical process requires identification of chemical cycles, estimates of efficiencies from mass and energy balances listed in detailed engineering flow. Bamberger and Richardson [31] list about 72 cycles most of which are conceptual in nature. Even now, laboratory data are generally sparse. However there are other forms of thermochemical processes namely solar, biomass etc. Currently feasibility of various thermochemical cycles and a possible laboratory scale thermochemical plant coupled with nuclear reactor is being analyzed by various researches funded by US Department of Energy [32]. There are various cycles namely sulfur-iodine cycle, hybrid sulfur cycle, calcium-bromine cycle and alternative thermochemical cycles, which are identified by USDOE for viability analysis of the process as well as the plant. The hybrid solar 
thermochemical cycles are also under review. Solar thermochemical processes convert radiant energy into chemical energy [33]. The objective of solar thermochemical processes is to identify thermochemical water- splitting cycles suitable for solar interfaces from the viewpoint of thermodynamics, chemical process engineering, costs and their potential environmental impact [34]. The primary work until now in this area has been identification/elimination of cycles based on numerous criteria; chemical reactions, chemical separations, process temperature, efficiency to name a few [35]. There are three notable processes namely Bunsen reaction involving iodine and thermal decomposition of HI, UT-3 thermochemical cycle and $\mathrm{Zn} / \mathrm{ZnO}$ process. The potential heat sources for the high temperature processes are being identified as solar thermal concentrators and central receiver systems and nuclear reactors [34]. Hence all these studies suggest that solar thermochemical process technology is a long-term prospect for hydrogen production. There are different suitable thermochemical processes for conversion and recycling of carbonaceous materials such as biomass. The processes include pyrolysis, gasification, liquefaction and supercritical fluid extraction [36]. All these processes appear to be attractive economically and are a feasible option. However the hydrogen gas produced normally contains other constituents and hence separation and purification of hydrogen becomes compulsory. Nowadays methods like $\mathrm{CO}_{2}$ absorption, drying/chilling and membrane separation have been successfully developed for hydrogen purification $[37,38]$. Hence biomass thermochemical conversion processes especially newly developed gasification types are expected to be commercially available in the near future [39]. 


\subsubsection{Hydrogen production from other processes}

Most methods of hydrogen production involve the splitting of water, and the source of energy for water splitting differentiates the production method. The work in this thesis deals mainly about electrolysis of water to produce hydrogen; however there are other methods which can be used to produce hydrogen. Solar energy is the most abundantly available renewable energy source for hydrogen production. Based on solar energy the various processes in producing hydrogen can be classified as:

a. Thermolysis by using concentrated solar energy

b. Biological methods using algae and cyanobacteria

c. Photolysis of water

Of these processes certain biological processes, may use sugars instead of water as the source of hydrogen.

\subsubsection{Thermolysis}

Thermolysis of water involves heating water to temperatures of about $3000 \mathrm{~K}$ to decompose it into hydrogen and oxygen. This method of hydrogen production is theoretically a very efficient mode of producing hydrogen. The fact that solar energy is used to heat the water up makes this process a more environmentally friendly approach to produce hydrogen. Solar concentrators are used to focus the suns energy onto the water and raise it to the desired temperature to trigger the decomposition of water. The work by G. Olalde et al. showed a more improved solar design for thermolysis of water. Their study used a refractory material $(\mathrm{ZrO} 2)$ as target material to heat up the water and the suns energy is focused onto this refractory material using parabolic mirrors mounted on heliostats. The study also showed that the immediate quenching of the products of 
disassociation prevented the recombination of products into water. The study also pointed out that the hydrogen bubbles produced were small, and would prevent explosion [40]. The study by H. Barnert showed the heat from high temperature nuclear reactor could be used for thermolysis of water. Hence thermolysis of water is considered as one of the potential methods of hydrogen production in near-future.

\subsubsection{Biological method}

Biological hydrogen production involves bacterial chemical reaction to produce hydrogen. Bacteria can produce hydrogen through oxygenic or anoxygenic reactions, with sunlight as their source of energy. Anoxygenic bacteria basically react with organic acids in the presence of sunlight to produce hydrogen and oxygenic bacteria react with water and sunlight to produce hydrogen [41]. There are certain types of green algae that have been found to produce hydrogen efficiently. Cyanobacteria are a certain type of bacteria that live under nitrogen rich environments, and these bacteria have been found to produce hydrogen reacting with organic compounds such as bio waste and sunlight to produce hydrogen. The biggest drawback of this system of hydrogen production would be the quantity of hydrogen production and the efficiency of recovering the produced hydrogen.

\subsubsection{Photolysis}

Photolysis of water utilizes a photovoltaic cell and an electrolytic chamber built in system. The photovoltaic cell would basically provide the electrical energy to split the water into oxygen and hydrogen. This type of hydrogen production is found to be very efficient and cost effective. A study by the Swiss federal institute uses new nanoparticle 
photovoltaic material which has very good energy conversion efficiency to produce highly efficient rates of hydrogen production [42]. However large scale industrial production of this process also requires research and development efforts on multiple fronts.

There are also numerous other techniques under development like titania nanotube arrays for photo-cleavage of water [43], Zirconium-Titanium Phosphates for photo induced water splitting [44] and lime- enhanced coal gasification [45] are some of the several approaches proposed for hydrogen production. Most of the novel techniques proposed for hydrogen production are only prototypes. Of these varied processes proposed for hydrogen production many need to be proved competitive against existing technology for cost, sustainability and performance.

\subsection{Electrochemical gasification of coal}

\subsubsection{Overview}

An electrochemical process was proposed by Coughlin and Farooque which converts coal and water into two separate gaseous products, one comprising essentially gaseous oxides of carbon and other essentially pure hydrogen [2]. Unlike other methods employed for hydrogen production, the process takes place at mild temperatures (even room temperature) and the gaseous products are free of impurities such as ash, tar and sulfur compounds. The process in this context causes electrolysis of water to hydrogen by utilizing the electrons in coal to lower the potential of operation. In this process, compared to conventional water electrolysis, less energy has to be supplied as electricity. However from another standpoint it can be considered that coal is gasified by reaction 
with water. In the process the externally supplied electrons from coal make the process thermodynamically feasible at low temperatures, otherwise large amounts of thermal energy would be required to carry out the reaction. Conventional production of hydrogen from coal using steam-carbon reaction requires high temperatures $\left(800^{\circ} \mathrm{C}\right)$. Also synthesis gas must be purified to remove sulfur compounds and other impurities followed by water-gas shift reaction to shift the $\mathrm{CO} / \mathrm{H}_{2}$ ratio. The current process however produces relatively pure streams of carbon oxides in the anode compartment and hydrogen at the cathode. The oxidation currents of the proposed reactions were observed in [3]. The experiments were carried out at room temperature. At a particular cell potential different types of coals and carbons were oxidized under potentiostatic conditions with a fixed coal slurry concentration. Experiments carried out by Coughlin et al under aforementioned conditions indicated that the rate of oxidation falls gradually as the reaction proceeds and this indicates coal consumption during the process. Various means to recover the coal were also listed in their studies. Their experiments were carried out with six different coal samples namely Montana rosebud char, North Dakota lignite, Pittsburgh coal, Illinois no.6 and Montana Rosebud coal. The reactivities of these different coal types were reported [2]. However in all the above analysis, only the carbon content in the coal was studied since coal contains a wide variety of organic compounds rich in carbon. The ash of coal contains some amount of iron. Literature suggests that the iron content in coal is actually oxidized, which causes the coal slurry to be oxidized [46]. They suggest that the voltammetric behavior for iron (II)/iron (III) is similar to that of coal slurry. On analyzing the mechanism thoroughly, Dhooge et al suggests that coal is oxidized through the catalytic mechanisms along with iron [47]. They report that rather 
than coal particles, compounds or ions from the coal that are soluble in acid solution causes the anodic oxidation. In another work by Dhooge et al, FTIR studies of electrolysis of coal were carried out [48]. They report that water is intimately involved in the oxidation mechanism. Water is the source of oxygen for production of carbon oxides similar to the coal gas reaction for the production of hydrogen and carbon monoxide. They suggest that the electrochemical gasification reaction is similar to coal gasification in terms of anodic oxidation. Their studies also indicate that both oxygens required for the formation of $\mathrm{CO}_{2}$ are added in two separate steps. The first step involves the formation of quinoid group followed by conversion of quinine to $\mathrm{CO}_{2}$. Hence it is to be noted that the carbon dioxide formed in this reaction is from the solvent water and not from carbonates or other carbon oxygen compounds extant in coal. The proposed reactions, energy requirements for the reactions and other factors to be considered in electrochemical gasification of carbons are listed in the sections to follow.

\subsubsection{Proposed reactions}

The chemical reactions involved in some of the well known commercial hydrogen production processes are discussed in detail in this section. Conventional water electrolysis process has been known since the $18^{\text {th }}$ century and industrial process exists beginning about 1900. The electrochemical gasification of coal equations are laid out considering only the carbon in coal [2]. The reaction at the anode which is the oxidation of coal is postulated by the half cell reaction:

$$
C(s)+2 \mathrm{H}_{2} \mathrm{O}(\mathrm{l}) \rightarrow \mathrm{CO}_{2}(g)+4 \mathrm{H}^{+}+4 e^{-}
$$

and the corresponding half cell reaction at the cathode:

$$
4 H^{+}+4 e^{-} \rightarrow 2 H_{2}(g)
$$


The net sum of the reactions (1) and (2) is the predominant reaction in the electrochemical gasification of coal.

$$
C(s)+2 \mathrm{H}_{2} \mathrm{O}(\mathrm{l}) \rightarrow 2 \mathrm{H}_{2}(g)+\mathrm{CO}_{2}(g)
$$

In conventional steam- gasification, the product is a complex mixture containing $\mathrm{H}_{2}, \mathrm{CO}$, $\mathrm{CO}_{2}$ and impurities. Instead the electrochemical gasification process produces relatively pure streams of carbon oxides in the anode compartment and hydrogen at the cathode. The conventional steam gasification equations are listed and it is important to distinguish the energy requirements for the process from electrochemical gasification. The well known steam - carbon reaction given by:

$$
\mathrm{C}(\mathrm{s})+\mathrm{H}_{2} \mathrm{O} \rightarrow \mathrm{CO}(g)+\mathrm{H}_{2}(g)
$$

The reaction is strongly endothermic and at ordinary temperatures the equilibrium for the reaction is highly unfavorable. The reaction is carried out at temperatures sufficiently high $\left(\sim 800^{\circ} \mathrm{C}\right)$ to assure favorable equilibrium. Also the endothermic heat of reaction required is supplied by gasifying the coal by treating it with a mixture containing both steam and oxygen. Thus part of coal is combusted as below:

$$
C(s)+\mathrm{O}_{2}(g) \rightarrow \mathrm{CO}_{2}(g)
$$

The heat released by reaction (5) provides the thermal energy and hence the necessary high temperature for reaction (4) is supplied. The energy required for all these processes are in discussions to follow. The detailed discussion about coal gasification is in [50]. The conventional water electrolysis reactions also needs to be listed in order to learn the energy requirements for the process. In conventional water electrolysis at the cathode pure hydrogen in produced.

$$
2 \mathrm{H}^{+}+2 e^{-} \rightarrow \mathrm{H}_{2}
$$


At the anode the reaction is:

$$
\mathrm{H}_{2} \mathrm{O} \rightarrow 1 / 2 \mathrm{O}_{2}+2 \mathrm{H}^{+}+2 e^{-}
$$

Hence the net reaction is water split into $\mathrm{H}_{2}$ and $\mathrm{O}_{2}$ molecules.

$$
\mathrm{H}_{2} \mathrm{O} \rightarrow \mathrm{H}_{2}+1 / 2 \mathrm{O}_{2}
$$

The conventional electrolysis process in alkaline media utilizes energy alone is also relevant in terms of production of hydrogen from water [49]. The reaction for such a reaction is listed as:

At cathode: $2 \mathrm{H}_{2} \mathrm{O}+2 e^{-} \rightarrow \mathrm{H}_{2}+2 \mathrm{OH}^{-}$

At anode: $\quad 2 \mathrm{OH}^{-} \rightarrow \mathrm{H}_{2} \mathrm{O}+1 / 2 \mathrm{O}_{2}+2 e^{-}$

Net reaction: $\mathrm{H}_{2} \mathrm{O} \rightarrow \mathrm{H}_{2}+1 / 2 \mathrm{O}_{2}$

Another method which uses only thermal energy and several complex cyclic processes are [49] shown:

$$
\begin{aligned}
& \mathrm{SO}_{2}+\mathrm{I}_{2}+\mathrm{H}_{2} \mathrm{O} \underset{1100 \mathrm{~K}}{\longrightarrow} \mathrm{SO}_{3}+2 \mathrm{HI} \\
& \mathrm{SO}_{3} \underset{1000 \mathrm{~K}}{\longrightarrow} \mathrm{SO}_{2}+1 / 2 \mathrm{O}_{2} \\
& 2 \mathrm{HI} \underset{600 \mathrm{~K}}{\stackrel{\longrightarrow}{\longrightarrow}} \mathrm{H}_{2}+\mathrm{I}_{2}
\end{aligned}
$$

Net: $\quad \mathrm{H}_{2} \mathrm{O} \rightarrow \mathrm{H}_{2}+1 / 2 \mathrm{O}_{2}$

There are also hybrid methods which utilize both thermal and electrical energy in a cyclic process [49]:

Electrolysis: $2 \mathrm{H}_{2} \mathrm{O}+\mathrm{SO}_{2} \rightarrow \mathrm{H}_{2} \mathrm{SO}_{4}+\mathrm{H}_{2}$

Thermal: $\quad 2 \mathrm{H}_{2} \mathrm{SO}_{4} \rightarrow 2 \mathrm{H}_{2} \mathrm{O}+2 \mathrm{SO}_{2}+\mathrm{O}_{2}$ 
Net: $\quad 2 \mathrm{H}_{2} \mathrm{O} \quad \rightarrow \quad 2 \mathrm{H}_{2}+\mathrm{O}_{2}$

The widely used methods for practical purposes are the ones which involve thermal energy and fossil fuels. The carbon of the fossil fuel becomes the acceptor of 'oxygen' from water. However combining the electrical energy with fossil fuel to produce hydrogen was first reported by Coughlin and Farooque, the reactions for which are listed above.

\subsubsection{Energy requirements}

Conventional water electrolysis in principle requires a theoretical thermodynamic electrical energy input of $56.7 \mathrm{kcal} / \mathrm{g}$-mol of $\mathrm{H}_{2} \mathrm{O}$ and a corresponding theoretical driving potential of about $1.23 \mathrm{~V}$. The energy input required is calculated based on the Nernst equation. The relation between free energy and cell potentials needs to be reviewed before considering the electrochemical gasification reactions. The change in Gibbs free energy associated with a chemical reaction is an indicator of whether the reaction will proceed spontaneously. The Gibbs free energy at any moment of time is described as the enthalpy of the system minus the product of temperature times the entropy of the system.

$$
G=H-T S
$$

The Gibbs free energy of the system is a state function because it is defined in terms of thermodynamic properties that are state functions. Hence the change in Gibbs free energy is equal to the change in enthalpy of the system minus the change in the product of temperature times entropy of the systems.

$$
\Delta G=\Delta H-\Delta(T S)
$$

If the reaction is at constant temperature the equation can be written as,

$$
\Delta G=\Delta H-T \Delta S
$$


The Gibbs free energy required for conventional water electrolysis is $56.7 \mathrm{kcal} / \mathrm{mol} \mathrm{H}_{2} \mathrm{O}$. For the coal gasification reaction which is strongly endothermic with $\Delta H^{\circ}=31.4$ $\mathrm{kcal} / \mathrm{mol}, \Delta G=21.8 \mathrm{kcal} / \mathrm{mol}$. Hence coal is gasified at $800^{\circ} \mathrm{C}$ using both steam and oxygen which makes the reaction exothermic with $\Delta H=-94.1 \mathrm{kcal} / \mathrm{mol}$. The reactions proposed by Coughlin and Farooque [2], require much less energy compared to conventional water electrolysis.

$$
\begin{aligned}
\Delta \mathrm{G} & =\Delta \mathrm{G}(\text { product })-\Delta \mathrm{G} \text { (reactants) } \\
& =-94.26\left(\mathrm{CO}_{2}\right)+2(56.7)=19.27 \mathrm{kcal} / 2 \mathrm{~mol} \mathrm{H}_{2} \mathrm{O} \\
& =9.6 \mathrm{kcal} / \mathrm{mol} \mathrm{H}_{2} \mathrm{O} \text { compared to } 56.7 \mathrm{kcal} / \mathrm{mol} \mathrm{H}_{2} \mathrm{O}
\end{aligned}
$$

The relationship between cell potential and free energy can be calculated from the reaction $\Delta \mathrm{G}=-\mathrm{n} \mathrm{F}$; where $\mathrm{n}$ is the number of free electrons involved in the reaction, $\mathrm{F}$ represents Faraday's constant and E the cell potential. Using this reaction, the corresponding cell potentials for conventional water electrolysis and electrochemical gasification can be calculated and compared. For conventional water electrolysis,

$$
\begin{aligned}
E^{0}= & -\frac{\Delta G}{n F}=\frac{-56.7 \times 10^{3} \times 4.18}{2 \times 9.6 \times 10^{4} \mathrm{C}} \frac{\text { cal.J }}{\text { cal }} \quad, F=9.6 \times 10^{4} \text { coulombs } \\
& =-1.23 \mathrm{~V} \quad\left(\text { volt }=\frac{J}{C}\right)
\end{aligned}
$$

This applied voltage of $E^{0}=1.23 \mathrm{~V}$ and associated power/energy used to electrolyze water to produce hydrogen is not practical because of its lower efficiency compared to hydrocarbon based processes (Rosen and Scott, Int. J. Hydrogen Energy, Vol. 23(1998), pages 653-659). The electrochemical gasification proposed requires only $-0.21 \mathrm{~V}$ as calculated below:

$$
\begin{aligned}
E^{0}=-\frac{\Delta G}{n F} & =\frac{-19.27 \times 10^{3} \times 4.18 \mathrm{~J}}{4 \times 9.6 \times 10^{4} \mathrm{C}} \\
& =-0.21 \mathrm{~V} \quad \cdots(7)
\end{aligned}
$$


These reactions were only proposed by Coughlin and Farooque and if true the energy requirements would be reduced approximately by a factor of six. However, the practical operating voltages at which they conducted their experiments were between $0.85 \mathrm{~V}$ and $1.0 \mathrm{~V}$. The greatly lower energy requirement for the electrochemical gasification process is from the consumption of coal which supplies the additional electrons required by the process. Alternatively electrochemical gasification can also be viewed as providing the free energy needed to drive the reaction at the anode by supplying an additional reagent in the form of electrons at a theoretical thermodynamic potential of $-0.21 \mathrm{~V}$. The energy required by the electrochemical gasification of coal is compared with the conventional water electrolysis in terms of a theoretical estimate $[2,51]$. The energy consumed by ordinary water electrolysis is given by $2 \mathrm{~N}_{\mathrm{H} 2} \mathrm{FE}_{2}$; where $E_{2}$ is the potential at which water electrolysis is conducted; $\mathrm{N}_{\mathrm{H} 2}$ is the number of moles of hydrogen produced and $\mathrm{F}$ the Faraday's constant. The energy required by electrochemical gasification is given by,

$$
E \int_{0}^{t} i d t+N_{C}\left(-\Delta H_{B}\right)
$$

where $\mathrm{E}$ is the operating potential; $\mathrm{i}$ is the anodic rate of electrochemical gasification; $N_{C}$ is the number of mol of carbon consumed; and $\Delta H_{B}$ is the enthalpy of combustion of carbon to $\mathrm{CO}_{2}$. The expression can be simplified by approximating the operating potential to be constant $\mathrm{E}$, and substituting

$$
\mathrm{NH}_{2}=\int_{0}^{t} i d t / 2 \mathrm{~F} \text { and } \mathrm{N}_{\mathrm{C}}=1 / 2 \mathrm{NH}_{2}
$$


Eliminating $\int_{0}^{t} i d t$ and $N_{C}$ the total energy consumed for electrochemical gasification is,

$$
2 \mathrm{FNH}_{2} \mathrm{E}+1 / 2 \mathrm{NH}_{2}\left(-\Delta \mathrm{H}_{B}\right)
$$

The relative energy unit (REU) is equal to $\left(\frac{\text { ordinary electrolysis }}{\text { coal - assisted electrolysis }}\right)$

$$
\begin{aligned}
& =\frac{2 N_{H 2} F_{2}}{2 F N H_{2} E+1 / 2 N H_{2}\left(-\Delta H_{B}\right)} \\
& =\quad E_{2} /\left(E+\left|\Delta H_{B}\right| / 4 F\right)
\end{aligned}
$$

We know that $\Delta H_{B}=94,100 \times 4.18 \mathrm{~J} \mathrm{~mol}^{-1}$ and $\mathrm{F}=96500 \mathrm{C}_{\text {equiv }}{ }^{-1}$. Hence

$$
\mathrm{REU}=E_{2} /(E+1.02)
$$

The above factor is a first order approximation of the amount of energy from each source and hence provides a rough feeling for efficiency. The energy required for conventional water electrolysis comes solely from electricity. However in electrochemical gasification about half the energy is supplied by coal and other half from electricity. Practical values of $E_{2}$ for conventional water electrolysis are about $2 \mathrm{~V}$ and for electrochemical gasification proposed by Coughlin $\mathrm{E} \simeq 1 \mathrm{~V}$. Though the relative energy unit for both the reactions is the same, with the increased energy supplied by coal, the energy required as electricity goes down. Also they suggest that the total energy requirement for coalassisted water electrolysis can be improved by conducting it at higher temperatures. 


\subsubsection{Other factors}

\subsubsection{Effect of coal}

The work reported by Coughlin et al reports all the results in terms of oxidation rates [3]. Increasing coal concentration i.e. coal-to-electrolyte loading increases oxidation rate. Also increasing temperature leads to an increase in current. The particle size of coal also affects the rate of electrochemical oxidation of coal. The reasons for such behavior can be attributed to:

1) The depth of penetration of the hydrodynamic boundary layer at an electrode depends on the particle radius [52]. If the reaction site is the particle surface, smaller particles with high surface area should react more rapidly on a unit mass basis.

2) The particle size versus chemical reactivity classification can be done by sieving coal into several different fractions based on particle size.

Through experimental observations it is verified that smaller particles provide higher rates during electro-oxidation proving the conventional notion of the chemical reactivity of the solid particles.

\subsubsection{Analysis of gases produced}

A coulombic efficiency close to $100 \%$ is claimed by Coughlin et al based on measured current values integrated over time. The anodic compartment contained a mixture of $\mathrm{CO}_{2}$ and CO. Due to the changes in population of surface oxides on the coal the composition of the anode gas varies as the reaction proceeds. The gas generated at the anode is mostly $\mathrm{CO}_{2}$ with lesser amounts of $\mathrm{CO}$. The $\mathrm{CO}$ concentration further reduces after most of the 
coal is consumed beyond which the mechanism itself appears to change. The volume of the gases collected at the cathode to anode ranged from about 9.1 to 3.7 [3]. The higher ratios were obtained at the beginning of the experiment but with a following decrease. As stated earlier, according to reaction stoichiometry this ratio for coal gasification reaction should be 2.0. However the accumulation of oxygen on coal particles in the form of functional and groups such as $-\mathrm{COOH},-\mathrm{CHO}$ and $\mathrm{CH}_{2} \mathrm{OH}$ and the like leads to higher ratios. Also the coal used has some hydrogen content which is also a reason for higher ratios.

\subsubsection{Effect of potential and activation energy}

As with any electrolysis, it is true in this case also that higher the potential greater the oxidation current. The activation energy is the minimum energy needed for the reaction to occur expressed in KJ. An Arrhenius relationship to the measured data plotted in the temperature range $25-110^{\circ} \mathrm{C}$ can be used to determine the activation energy. The activation energy was estimated to be between 9 to $11 \mathrm{Kcal} \mathrm{mol}^{-1}$, based on the operating conditions. The sulfuric acid concentration of the electrolyte did not affect the activation energy. However with increasing coal concentration, a small change in activation energy was observed.

\subsubsection{Role of carbon}

Carbon particles of large surface area find varied applications such as adsorption, catalysis, and physics-chemical processes [53]. The reason for such application can be attributed to carbon's crystalline structure, microscopic physical structure, electronic properties and sometimes the presence of impurities within the carbon. Carbon itself 
gives rise to some catalytic properties and carbon may display electronic properties as conductor, semiconductor or insulator based on method of preparation and pretreatment. Hence treatment of carbon catalyst to influence its electronic properties may alter its activity and selectivity for a particular kind of reaction. Oxidation and formation of oxides on the edges of layer planes can be considered as one kind of treatment which localizes $\Pi$-electrons in surface states and lead to more semi conductivity. There are several reactions catalyzed by carbons including hydrogen-deuterium reaction, oxidationreduction, halogenation and polymerization. In the reaction of interest (oxidationreduction) surface oxygen of catalysts participate in many reactions [54]. In the case of hydrogen peroxide decomposition, it has been shown that catalysis is due to the basic surface oxides on carbon but inhibited by acidic functional groups of chemisorbed oxygen. Also carbon can act as a sorbent when it has a specific affinity and accessible surface area. Selectivity not only depends on pore geometry but also by various specific contributions to the physical bond between carbon and adsorbate. The influence of surface oxygen seems to influence adsorption of nitrobenzene and benzene sulfonate from aqueous solutions. Although the precise mechanisms remain in doubt, the behavior of carbon as catalyst is established. 


\section{EXPERIMENTAL SETUP}

\subsection{Overview}

This chapter provides the details about the electrochemical setup used to carry out the experiments. The basic setup is a simple three electrode electrochemical setup with working, counter and reference electrodes. The nature and dimensions of the electrodes are discussed in detail. The details about the gas chromatograph used in the study and analysis performed with the chromatograph are also listed in detail.

\subsection{Setup \& Instrumentation}

A schematic of the basic three electrode setup used is shown in Figure 3.1 [55]. There are three compartments in the setup. The anode compartment which contains the working electrode is the center compartment. The electrolyte in the anode compartment is $3.7 \mathrm{M}$ sulfuric acid along with activated carbon. High purity, high surface area activated carbon was used (PICA carbon with surface area of $1000 \mathrm{~m}^{2} / \mathrm{g}$ supplied by PICA, USA Inc.). The compartment is stirred continuously with a magnetic stirrer to avoid bubble effect (explained later). The working electrode used in the setup is a platinum plate (working area $6.8 \mathrm{~cm}^{2}$ ) attached with a platinum wire to allow electrical connections. The cathode contains only $3.7 \mathrm{M}$ sulfuric acid as the electrolyte and it contains the counter electrode. The counter electrode is platinum coil of area $2.5 \mathrm{~cm}^{2}$. The third chamber consists of the reference electrode with only $3.7 \mathrm{M}$ sulfuric acid as the electrolyte. The reference electrode is standard $\mathrm{Ag} / \mathrm{AgCl}$ reference electrode (Metrohm 6.0726.100). The counter and reference compartments are separated from the anode compartment with a glass frit. 
The electrodes are connected to the leads of a potentiostat (BAS model 100B). The BAS $100 \mathrm{~B}$ model is an electrochemical analyzer with computer controlled data acquisition system. The evolved gases are analyzed by a Gas Chromatograph (GC) model $8610 \mathrm{C}$ from SRI instruments. The purpose of glass frit, choice of electrodes and electrolyte are explained in detail in the forthcoming sections.

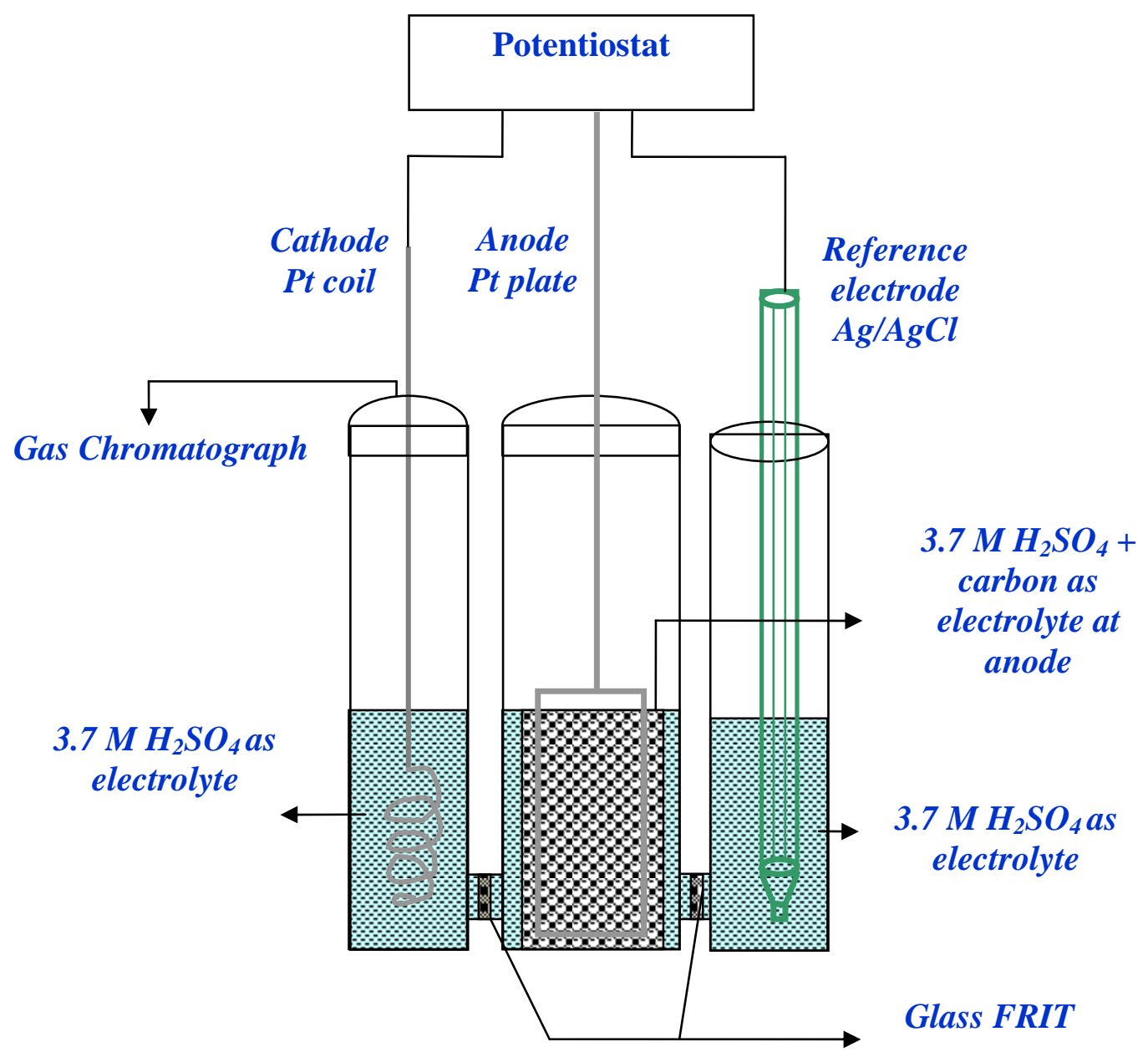

Figure 3-1.Schematic of the three-electrode cell used in the experiments. The surface area of the $\mathrm{Pt}$ anode (cathode) is $6.8 \mathrm{~cm}^{2}\left(2.5 \mathrm{~cm}^{2}\right)$. The contents of the anode compartment were constantly stirred by a magnetic stirrer (not shown) [1]. 
The electrodes used and the electrochemical cell used are shown. Figure 4 shows the platinum plate, platinum coil and the cell used. Figure 5 is the electrochemical setup along with the BAS potentiostat. The Gas chromatograph model $8610 \mathrm{C}$ is shown in figure 6 .
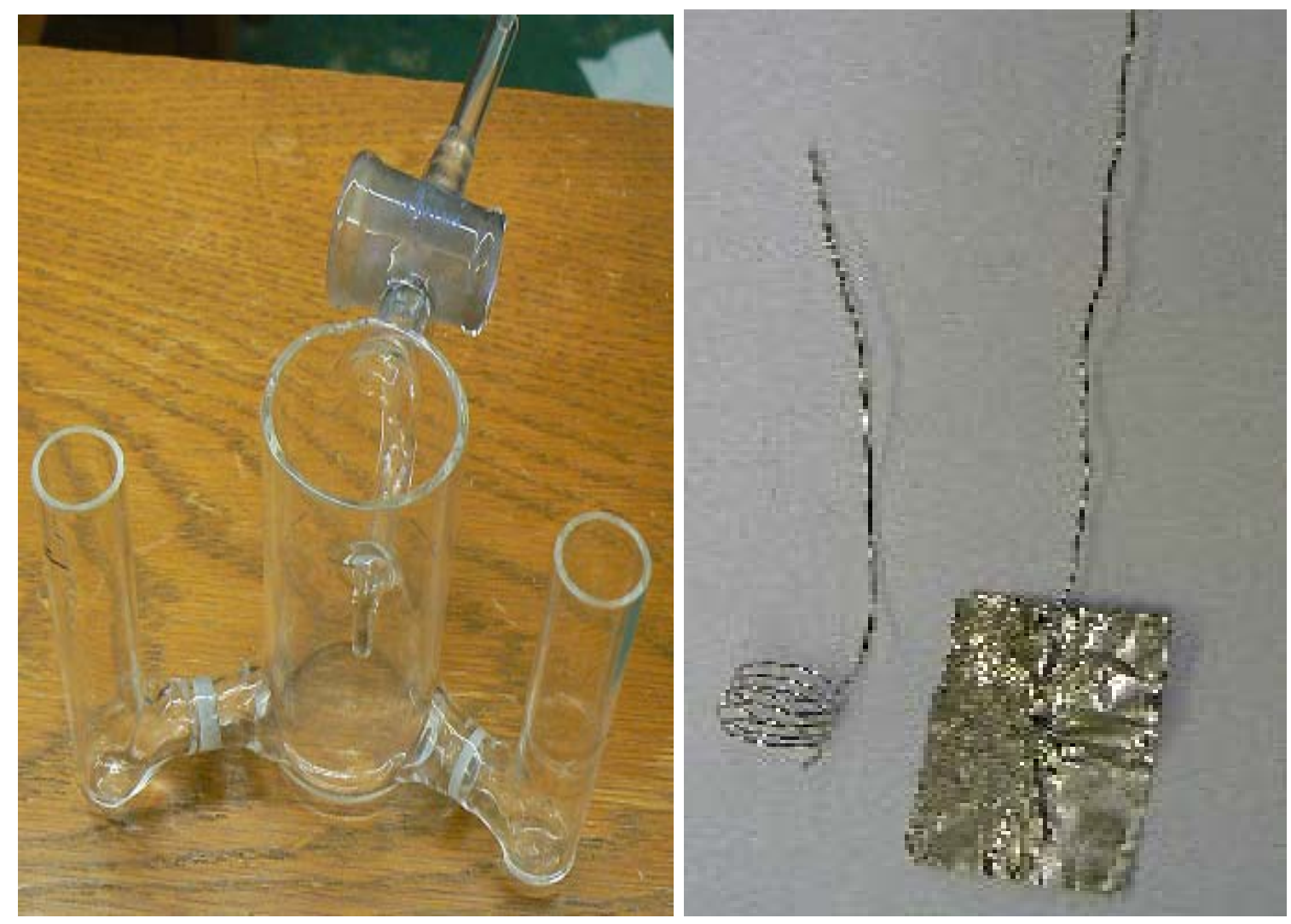

Figure 3-2.Electrodes and Electrochemical cell used 


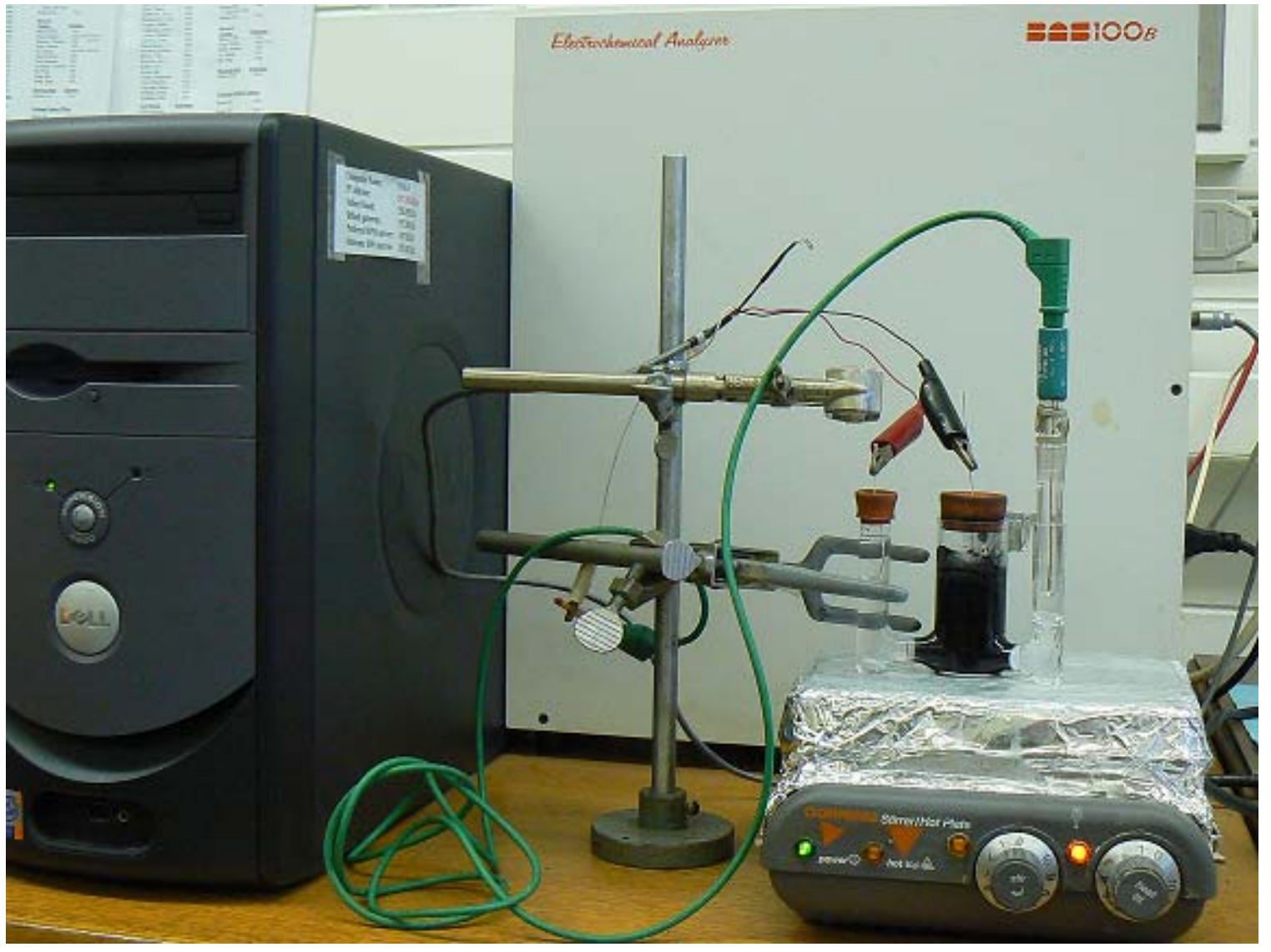

Figure 3-3. Electrochemical setup along with potentiostat 


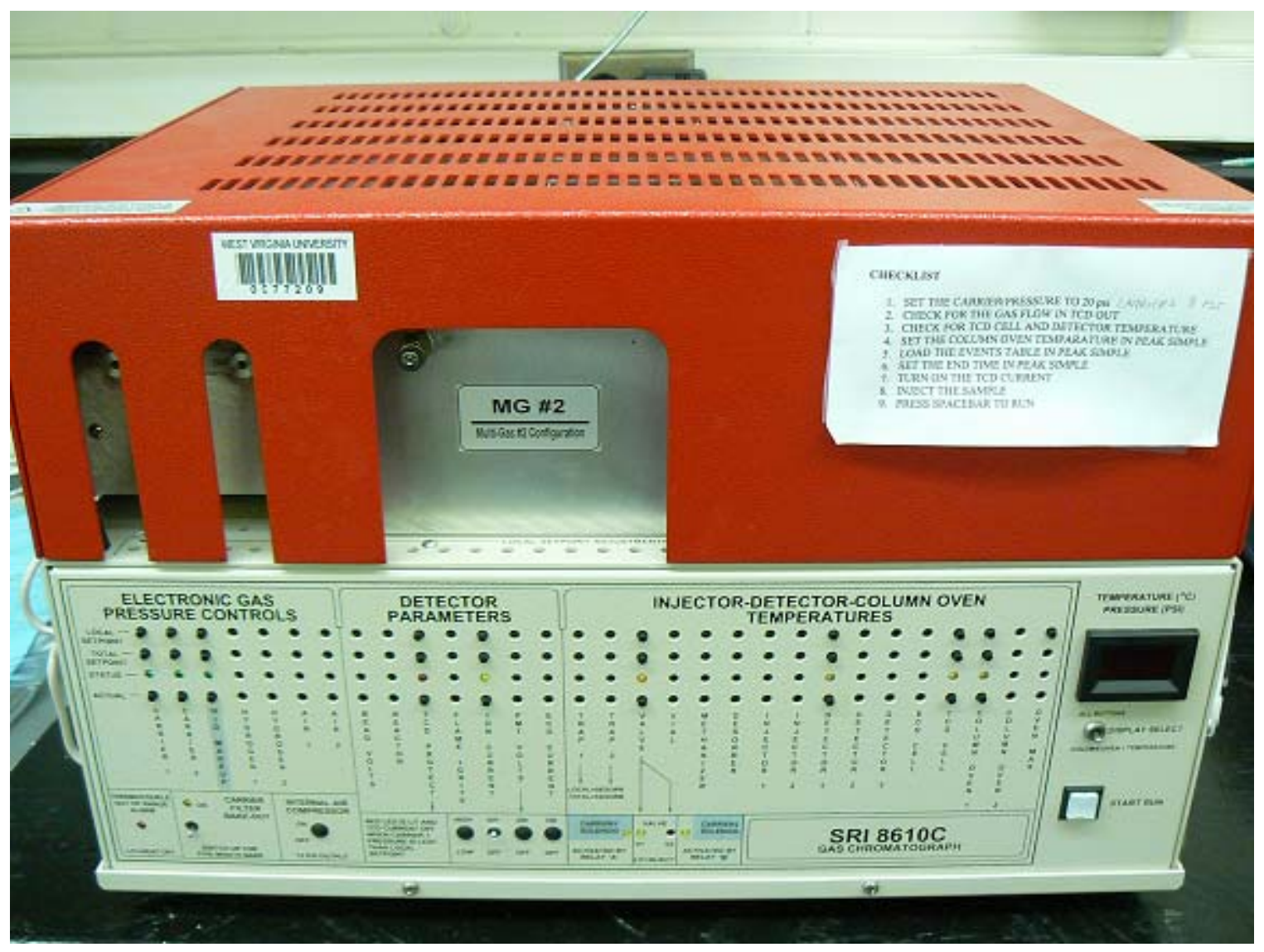

Figure 3-4. Gas Chromatograph Model 8610C

\subsection{Experimental procedure}

The experiments were carried out as follows. In each experiment the operating potential $E^{0}$ was kept constant and the time required to electrolyze approximately the same amount of electrolyte in the cathode cell was measured. Also the current $I_{0}$ was simultaneously measured. The time required to produce the same amount of hydrogen is termed as $t_{H}$ and amount of $\mathrm{H}_{2}$ produced per $\mathrm{W}$ h of energy used is termed as $A_{H}$. A fixed volume of the gas produced in the cathode was then injected by a syringe into the GC column. The GC output is a plot of retention time vs. amplitude. The area under the $\mathrm{H}_{2}$ peak was noted for each experiment. This way for each $E^{0}$, the area under the peak was approximately the 
same but with different $t_{H}$ and $I_{0}$. Since the area under the peak was only approximately constant, the time $t_{H}$ was normalized for exact peak areas (we chose 1000 units). The current $I_{0}$ recorded had some fluctuations presumably due to stirring of the electrolyte in the anode compartment and hence the intermittent contact of carbon particles with the anode. These fluctuations are the source of primary uncertainties in the data to be shown and are indicated with error bars in all the plots. Thus in our experiments for every $E^{0}$ (in the range of 0.1 to $1.8 \mathrm{~V}$ ), the time $t_{H}$ required to produce exactly the same amount of hydrogen and the current $I_{0}$ in the circuit are determined. Also in order to estimate the effect of carbon for a particular $E^{0}$ the carbon concentration added in the anode compartment was varied and the time $t_{H}$ and $I_{0}$ were noted. The potentials listed throughout the work are with respect to standard hydrogen electrode (SHE) and so corrected for $E^{0}=0.22 \mathrm{~V}$ for $\mathrm{Ag} / \mathrm{AgCl}$. For every experiment, the electrolyte and the carbon added was replaced with a new solution.

\subsection{Electrode Electrolyte and other considerations}

The choice of electrodes and electrolytes in this work is based on the suggestions in the literature and hence it is appropriate to review them.

\subsubsection{Electrode}

In any electrolysis system, the electrode should satisfy the following characteristics [56]. They must be electronic conductors with the ability to provide a catalytic surface for the discharge of hydrogen or hydroxyl ions. The electrode material must provide a large surface area interface between the catalyst and the electrolyte. Also the electrode must have adequate sites for nucleation of the gas bubbles and provide a reasonable means for 
the detachment of gas bubbles so that they may separate from the electrolyte. There are various materials satisfying these conditions. However it is established that platinum assists the electrode process considerably and allows the reaction to proceed more rapidly than nickel. Also platinum has higher chemical as well as corrosion resistance. The platinum electrode used in the system is trouble free and maintenance free. After every run the working (platinum plate) and cathode (platinum coil) was just washed with deionized water. However suggestions for other electrode materials are made for future work.

\subsubsection{Electrolyte}

The choice of the electrolyte $3.7 \mathrm{M}$ sulfuric acid is found to be the optimum for water electrolysis [3]. Generally the electrolyte used must exhibit high ionic conductivity and it must be able to withstand voltages at which the cell operates so that the electrolyte itself does not decompose. It should not be volatile to be removed with the evolved gases. Also since the solution will encounter rapid changes in hydrogen ion concentrations at the electrodes, the electrolyte should have strong resistance to $\mathrm{pH}$ changes, i.e., a buffer solution. In practical applications, the above criteria can be met by strong acids or strong alkali. However since carbon is used, the solubility of $\mathrm{CO}_{2}$ in alkaline electrolytes could be problematic under certain circumstances. Buffer systems such as $\mathrm{CO}_{3}^{2-} / \mathrm{HCO}_{3}^{-}$can also be used. The advantage in this medium is that it is less corrosive than an oxidizing acid electrolyte which could possibly reduce cost of materials and reject $\mathrm{CO}_{2}$. Also $\mathrm{H}_{3} \mathrm{PO}_{4}$ which can withstand much higher temperatures than $\mathrm{H}_{2} \mathrm{SO}_{4}$ can be used. However

report [3] suggests sulfuric acid performance is better for electrochemical coal gasification. They have also established the conductive superiority of sulfuric acid over 
phosphoric acid and trifluoromethane sulphonic acid monohydrate solutions. Hence sulfuric acid is most preferred for electro chemical gasifications.

\subsubsection{Separator}

The electrodes need to be separated to prevent the electrodes from touching each other and shorting out. Also the gases produced should not mix together inside the cell. Hence the separator should be a porous diaphragm or matrix through which the electrolyte can pass. It should allow ionic conducting path from one side of the cell to the other. Also the pores should remain full of liquid so that gas cannot pass through. All separators should also be corrosion resistant. Also in the case of electrochemical gasification the carbon used should be isolated only to the anode. So in this case a glass frit was used as the separator. The frit porosity was chosen to be of porosity C (ace porosity) based on the particle size (particle size $\sim 140 \mu \mathrm{m}$ ) of the carbon used.

\subsubsection{Bubble effect}

The formation of bubbles as shown in figure 3.5 at the electrodes during electrolysis is an important electrical field and electrochemical process disturbance [57]. This causes an ohmic potential drop and hence contributes to higher energy consumption [58]. The presence of bubbles modifies the electrical properties, thermal properties, the electroactive species diffusive transport and the current density. The bubbles need to be forced to separate faster from the electrodes and ascend through the electrolyte. Hence the whole electrochemical cell is mounted on a magnetic stirrer (CORNING stirrer/hotplate) and stir bars are used both in the anode and cathode compartment thereby eliminating gas blanketing. 


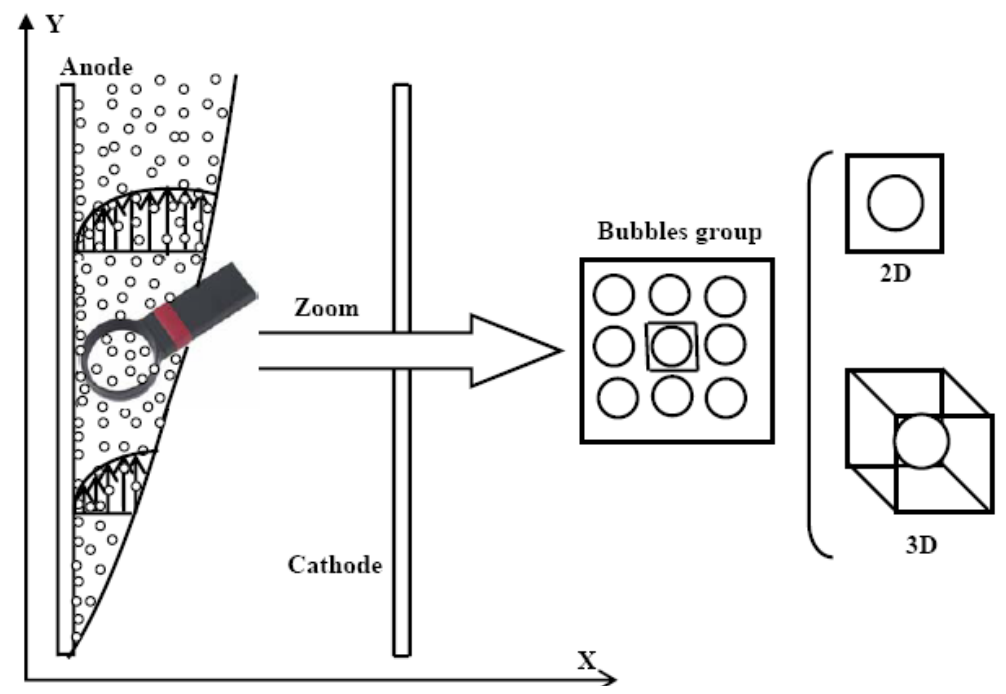

Figure 3-5.Presence of bubbles at the electrode. From macroscopic vertical electrode to insulated bubble [4].

\subsection{Gas chromatograph description}

\subsubsection{Gas chromatograph basics}

Chromatography in general can be termed as a separation technique for components of a mixture by a series of equilibrium operations. The separation of entities is a result of the portioning (differential adsorption) between two different phases, one large surface stationary phase and other a moving phase in contact with the first [59]. Gas chromatography is one in which the moving phase is a gas phase. The mixture to be separated and analyzed can be gas, liquid or solid. In any case, the conditions to be satisfied by the sample components are stability, set operating pressure, operating temperature and interaction with the column material and the mobile phase. The techniques behind separation of sample components are frontal analysis, displacement development or elution development. Frontal analysis is one in which the gas mixture is 
fed into a column containing solid packing and the component is separated based on its ability to become a sorbate. In the displacement development technique, the developer is contained in the moving phase which may be a liquid or gas. The moving phase need to be more sorbed than any sample components and there is always an overlap zone for each succeeding component. In the elution technique, the components travel through the column at rates determined by their solid packing. In this technique, at the end of separation, only the elutant remains in the column. Hence it is the most preferred over other techniques. Some of the terms to be discussed relevant to chromatography are retention time, resolution, peak area and selectivity. Retention time is the amount of time elapsed from the injection of the sample to the recording of the peak maximum. Resolution indicates the degree of separation between the peaks. Peak area refers to the area enclosed between peak and peak base and selectivity the lowest detection limit achieved by the detector. Since the GC is sensitive even up to parts per million the hydrogen produced in the cell could be detected over several voltage ranges. The hydrogen produced in the cell was calibrated with pure hydrogen produced from a hydrogen generator. There are numerous types of columns, detectors and analyzers available; the one used in the study is discussed below.

\subsubsection{C GC}

Model 8610 C GC (supplied by SRI instruments) was used for hydrogen analysis and quantification. The $8610 \mathrm{C} \mathrm{GC}$ is a Multiple Gas Analyzer capable of separating a wide variety of peaks [60]. The instrument consists of two packed columns, one molecular sieve and other hayesep column and a TCD detector. The carrier gas flow through the two different columns is turned ON and OFF individually at different times during the 
run thereby preventing co-elution of the gases. The carrier to Molecular sieve $13 \mathrm{X}$ column is turned on first thereby separating $\mathrm{H}_{2}, \mathrm{O}_{2}, \mathrm{~N}_{2}, \mathrm{CO}$ and $\mathrm{CH}_{4}$. Ultra High Pure nitrogen was used as the carrier gas hence hydrogen elutes from the first column as the first element. The second column can be used to separate all compounds in the $\mathrm{C}_{1}-\mathrm{C}_{6}$ range if needed. There are two separate carrier gas flows, each regulated by electronic pressure control through the software (peaksimple). The sample is injected through a sample inlet port. The carrier 1 flows through sample loop one to the molecular sieve column and then to the TCD detector through the "Tee". Carrier \#2 flows through the second column hayesep and through the "Tee" to the TCD detector. An event table determines the $\mathrm{ON}$ and $\mathrm{OFF}$ of either of the carriers. In this case since only hydrogen needs to be detected, the same carrier was used and only the molecular sieve column was used. The whole run was carried out in 7 minutes with a retention time of $\sim 0.5 \mathrm{~min}$ for hydrogen at a column oven temperature of $120^{\circ} \mathrm{C}$.

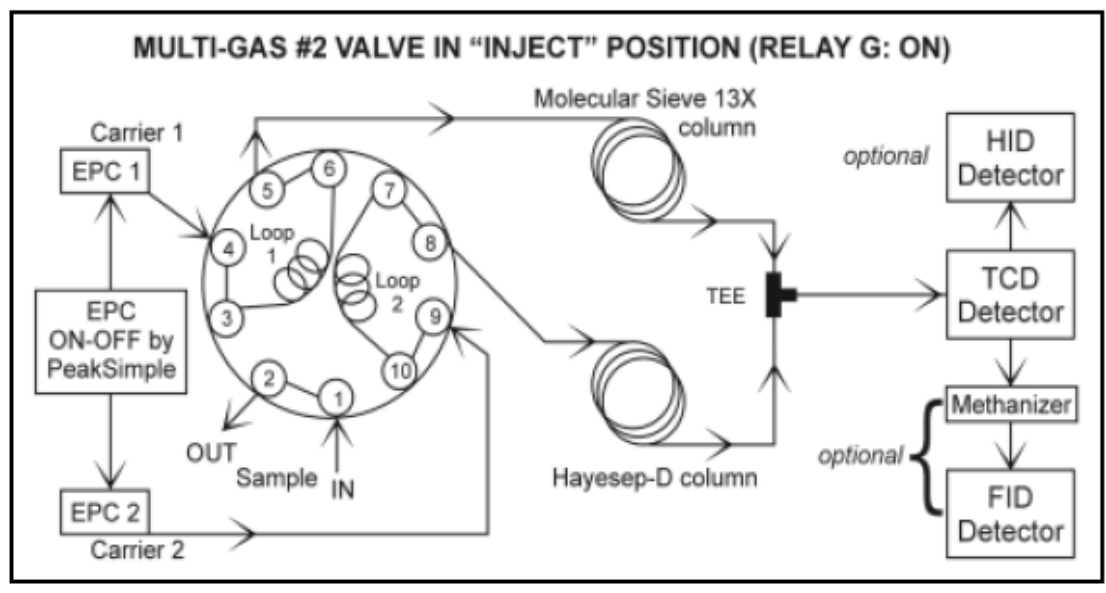

When the MG\#2 valve is in the INJECT position, carriers \#1 and \#2 flow through the sample loops, sweeping their contents to the columns.

Figure 3-6.Schematic and working of Multi Gas analyzer 8610 C GC [60] 


\subsubsection{GC column}

The column can be considered as the heart of the GC since this is where the actual separation of component takes place. The GC is equipped with two columns: Molecular sieve $13 \mathrm{X}$ and Hayesep D column. Since the work involves the use of the only molecular sieve column, it is considered in detail. The molecular sieve serves as the column packing and acts as adsorbents. They are also referred to as zeolites, which are synthetic alkali or alkaline-earth metal aluminium silicates and are utilized for the separation of hydrogen, oxygen, nitrogen, methane and carbon monoxide. These materials are separated using a molecular sieve because their pore size matches their molecular diameter. The molecular sieve $13 \mathrm{X}$ refers to the pore size of $13 \AA$ with sodium as the primary cations. The column oven temperature is another important parameter that affects the range of separation. The column temperature needs to be chosen appropriately so that optimum separation of components is achieved. An isothermal column temperature of $120^{\circ} \mathrm{C}$ was chosen for all our runs.

\subsubsection{TCD detector}

A thermal conductivity detector is a chamber in which an electrically heated element reflects changes in thermal conductivity within the chamber atmosphere and the measurement is carried out based on the change in electrical resistance of the element. The TCD is a Wheatstone bridge configuration and uses four general purpose tungstenrhenium filaments for sample analysis [61]. 


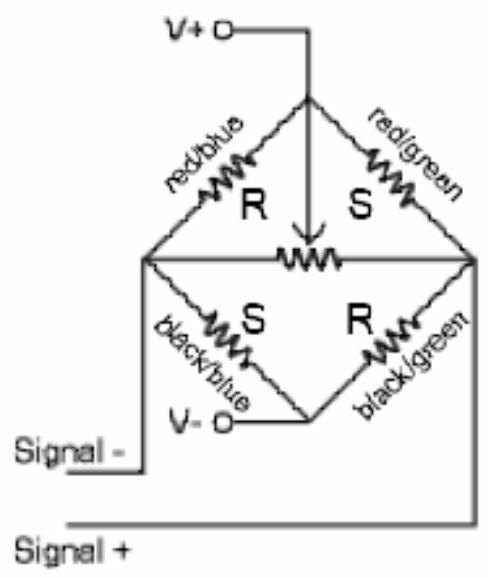

\section{Figure 3-7.TCD filament circuit [61]}

Two of the filaments are exposed to sample-laden carrier gas flow (provides the actual chromatographic operation) and two others with clean carrier flow (acts as reference signal). When the effluent from the column flows over the two sample stream filaments, the bridge current is unbalanced with respect to the reference signal. This deflection is converted to analog signal and then transmitted to the data system. The filament leads are color coded so as to provide an indication of wires connected to the terminal. 


\section{RESULTS AND DISCUSSION}

\subsection{Overview}

In this chapter, the results on carbon-assisted water electrolysis for applied potential ranges between $0.1 \mathrm{~V}$ and $1.8 \mathrm{~V}$ are reported. The following quantities are measured: (i) time $t_{H}$ to produce the same amount of hydrogen versus applied $E^{0}$ (ii) quantity $A_{H}$ representing the amount of hydrogen produced per W-hr of energy used and (iii) variations of $t_{H}$ and $A_{H}$ for different amounts of carbon used varying between 0.02 to 0.12 $\mathrm{g} / \mathrm{cm}^{3}$ of the electrolyte. The value of $A_{H}\left(\mathrm{H}_{2} / \mathrm{W}-\mathrm{hr}\right)$ is higher at lower voltages. However it requires a longer time (higher $t_{H}$ ) to collect the same amount of hydrogen meaning slower kinetics at the lower voltages. The results are compared with the parameters obtained in the conventional water electrolysis process. In that case measurable hydrogen production is observed only for $E^{0}>1.4 \mathrm{~V}$. To verify the data, two runs were carried out under similar conditions (potentials) and same carbon concentration. The data was closely reproducible in terms of current, time and hydrogen produced. However for the sake of clarity only one of the data sets (run 2) is used throughout the discussion here except when comparing both sets of data. A table with measured values of current, time and calculated values of power, energy requirements for selected $E^{0}$ values is also listed in the discussion to follow. Based on the overall considerations of $t_{H}$, and $A_{H}$ the most practical value for $\left|E^{0}\right|=0.5 \mathrm{~V}$ is suggested. Also after reviewing various carbon concentrations, $0.08 \mathrm{~g} / \mathrm{cm}^{3}$ of the electrolyte was found to be the optimum for lower voltages which are of primary interest. 


\subsection{Potential vs. Time and current}

In Figure.10, a plot of $t_{H}$ (time/same amount of $\mathrm{H}_{2}$ ) versus potential $E^{0}$ for run2 and the current measured in the circuit is shown. Although hydrogen production could be observed at voltages as low as $0.1 \mathrm{~V}$, the corresponding time required, $t_{H} \simeq 95 \mathrm{~min}$ is much higher, meaning slow kinetics. This slow kinetics at the lower voltages is perhaps the reason why the earlier experiments were limited to $E^{0}>0.7 \mathrm{~V}$ [2]. For $E^{0}=0.28 \mathrm{~V}, t_{H}$ drops to about $18 \mathrm{~min}$. Between $E^{0}=0.3$ and $0.68 \mathrm{~V}$, there is a further decrease in $t_{H}$. For $E^{0}>1.4 \mathrm{~V}, t_{H}$ decreases rapidly, where the current in the circuit also increases rapidly.

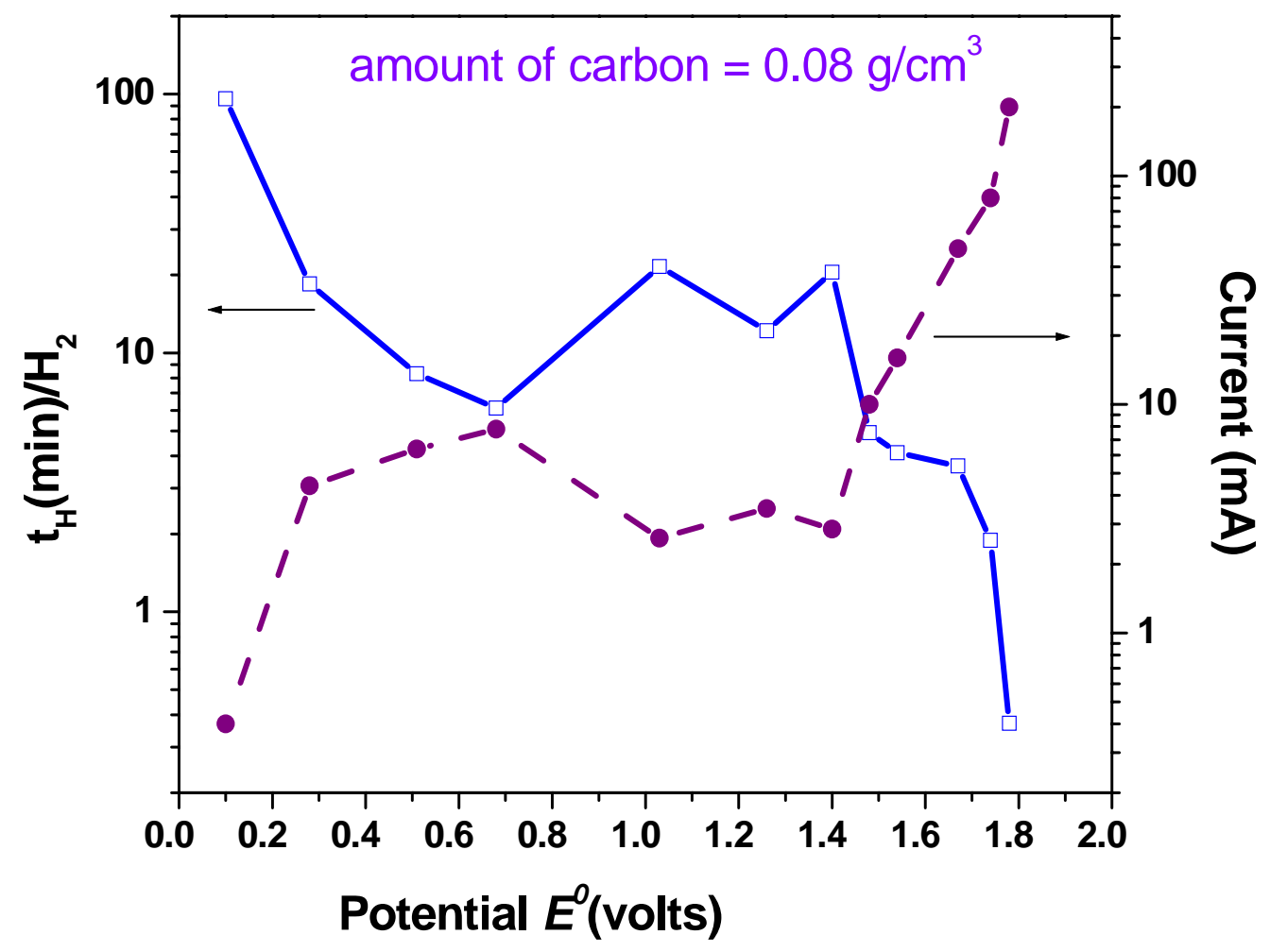

Figure 4-1.Time $t_{H}$ needed to produce the same amount of $\mathrm{H}_{2}$ and the current in the circuit are plotted against the applied potential $E^{0}$ vs SHE for run 2. 
Surprisingly for $1.0 \mathrm{~V}<E^{0} \leq 1.4 \mathrm{~V}, t_{H}$ goes through a relative maximum as if an energy barrier exists for these potentials. Such an effect was observed by Coughlin et al also. In their experiments a constant current was maintained and correspondingly the potentials were varied. A potential jump from $1.2 \mathrm{~V}$ to $1.7 \mathrm{~V}$ was observed to maintain the constant current indicating the onset of a different mechanism [3].

\subsection{Energy Calculations}

Before considering other plots it would be appropriate to consider the computations based on which the rest of the data were plotted. The table lists constant $E^{0}$ values,

\begin{tabular}{|c|c|c|c|c|c|c|}
\hline$E^{0}$ (volts) & $\begin{array}{c}\mathrm{I}_{0} \\
(\mathrm{~mA})\end{array}$ & $\begin{array}{l}\text { Power }=E^{0} \mathbf{I}_{0} \\
\left(10^{-4} \text { watts }\right)\end{array}$ & $\begin{array}{c}\mathbf{t}_{\mathrm{H}} \\
\left(\mathrm{min} / \mathbf{H}_{2}\right)\end{array}$ & $\begin{array}{c}\mathbf{R}_{\mathbf{H}} \\
\left(\mathbf{H}_{2} / \mathrm{min}\right)\end{array} \mid$ & $\begin{array}{c}E^{0} \cdot \mathbf{I}_{0} \cdot \mathrm{t}_{\mathrm{H}} \\
\left(10^{-4} \text { watt-hr/ } / \mathbf{H}_{2}\right)\end{array}$ & \begin{tabular}{|c|}
$A_{H}$ \\
$\left(10^{2}\right.$ \\
$H_{2} /$ watt-hr $)$
\end{tabular} \\
\hline 0.1 (Carbon) & $\overline{0.4}$ & $\overline{0.4}$ & 95.9 & $\overline{0.01}$ & $\overline{0.64}$ & 156.3 \\
\hline $\begin{array}{l}0.28 \text { (Carbon) } \\
\end{array}$ & $\overline{4.4}$ & 12.32 & $\overline{18.5}$ & $\overline{0.054}$ & 3.8 & 26.3 \\
\hline "0.51(Carbon) & 6.38 & 32.54 & $\overline{8.3}$ & 0.12 & 4.5 & 22.2 \\
\hline 1.78 (Carbon) & 200 & 3560 & 0.37 & 2.7 & 22.0 & 4.54 \\
\hline $\begin{array}{l}1.67 \text { (No } \\
\text { Carbon) }\end{array}$ & 65 & 1085.5 & 3.16 & 0.32 & 57.2 & 1.75 \\
\hline
\end{tabular}

Table 4-1.Measured and computed quantities for selected $E^{0}$ values with $(0.08$ $\mathrm{g} / \mathrm{cm}^{3}$ ) and without carbon. 
measured current and normalized $t_{H}$ values. As mentioned in the table the magnitude of power is calculated as the product of potential and current. The W-hr per unit hydrogen produced is simply the product of power and the normalized time since energy is calculated as an integral of power. The amount of hydrogen produced per W-hr is simply the inverse of the former quantity. It can be observed that in the experiments with carbon the energy consumption to produce the same amount of $\mathrm{H}_{2}$ increases sharply with voltage. However the time required appears to have the opposite trend. The value of current seems to influence the most in the case of energy requirements. Though the time required goes down, the energy requirements increases with increase in current. In experiments without carbon the time taken is higher, the energy to produce the same amount of $\mathrm{H}_{2}$ is higher and also the amount of hydrogen produced per W-hr is much lower.

\subsection{Amount of hydrogen produced}

Since energy consumed to produce $\mathrm{H}_{2}$ is a major issue for practical applications, a plot of $A_{H}$, representing the amount of $\mathrm{H}_{2}$ produced per $\mathrm{W}-\mathrm{hr}$ of energy used $\left(1 \mathrm{~W}-\mathrm{hr}=3.6 \times 10^{6}\right.$

J) against $E^{0}$ is shown for both runs 1 and 2. In the same plot, data for ordinary electrolysis without added carbon is also shown. Of course in ordinary water electrolysis, measurable $\mathrm{H}_{2}$ is not produced unless $E^{0}>1.4 \mathrm{~V}$ is applied. Also even with $E^{0}>1.4 \mathrm{~V}$ the amount of hydrogen produced per W-hr is lower than carbon assisted electrolysis in most of the cases. A semilog plot is used to accommodate all the data since the values for ordinary electrolysis was much lower compared to carbon-assisted electrolysis. An important result to be noted here is that $A_{H}$ in carbon assisted electrolysis increases with 
decrease in $E^{0}$. But this higher $A_{H}$ at lower $E^{0}$ values requires corresponding longer times $t_{H}$ needed to collect the same amount of $\mathrm{H}_{2}$. This can be considered as a tradeoff between energy and time, the choice of which is based on the potential $E^{0}$.

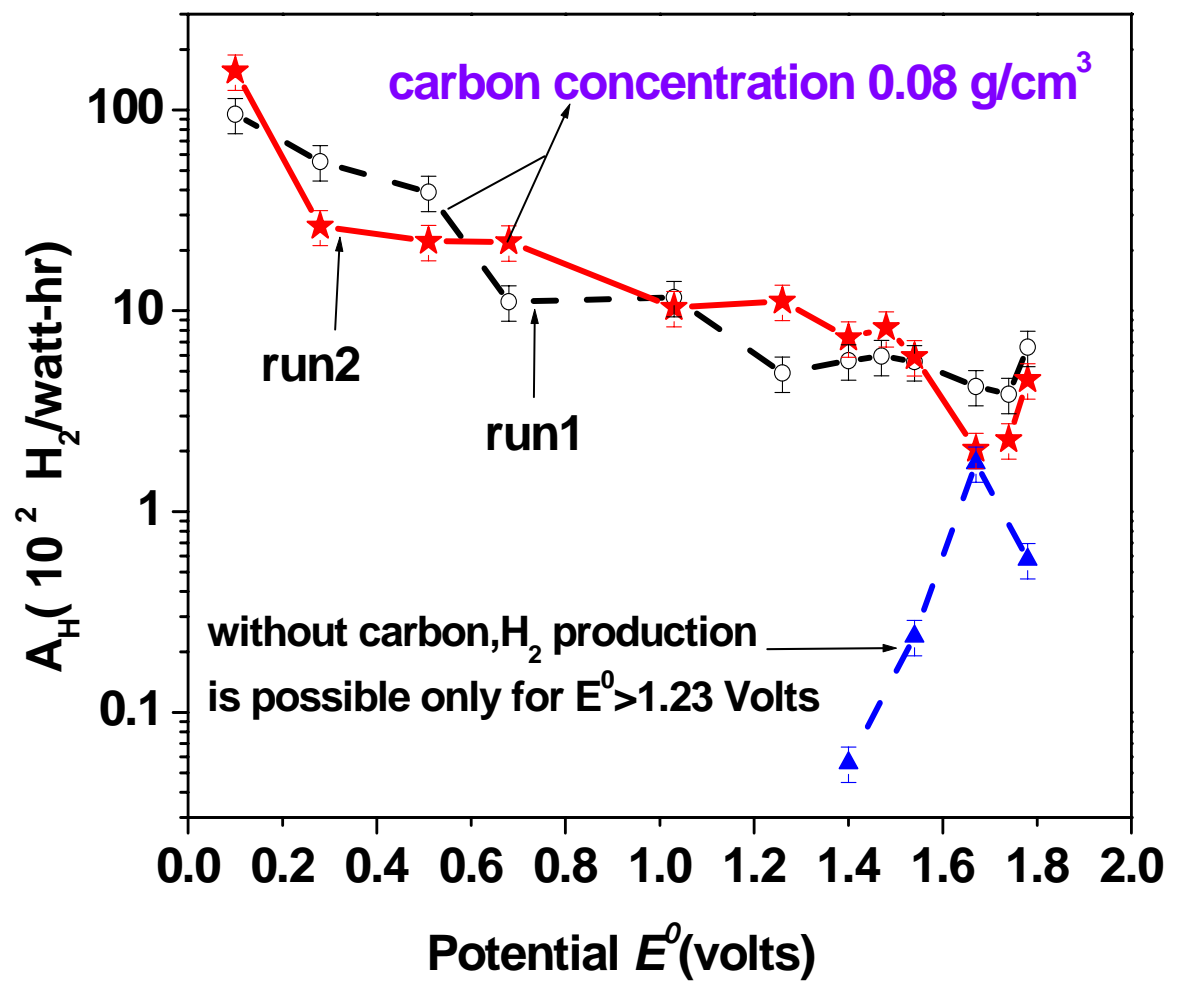

Figure 4-2. Quantity $A_{H}$ representing the amount of hydrogen produced per $\mathrm{W}$-hr of energy consumed is plotted against potential $E^{0}$.

\subsection{Influence of current on hydrogen produced}

In the experiments by Coughlin and Farooque [2, 3, 49], the hydrogen produced was monitored primarily by the current $I_{0}$ in the circuit, assuming proportionality between the two quantities. Since both quantities $\mathrm{H}_{2}$ and $I_{0}$ were measured in our experiments, a check on this linearity can be made. Our data in figure 9 validates this assumption 
approximately. As stated earlier, there is a definite slow down of $\mathrm{H}_{2}$ production prior to the threshold potential for ordinary water electrolysis. A theoretical understanding of the energy barrier and slow down is highly desirable. For such an understanding the mechanism behind carbon assisted electrolysis needs to be understood. The experiments with carbon involved a carbon concentration of $0.08 \mathrm{~g} / \mathrm{cm}^{3}$ of the electrolyte. The current for ordinary electrolysis without carbon is also shown for the voltages for which measurable hydrogen could be produced. The quantity "hydrogen per minute" is calculated as the amount of hydrogen (1000 units) produced divided by the time required $\left(t_{H}\right)$ to produce the same amount of hydrogen. As stated in the table earlier, it can also be seen that hydrogen produced is much smaller in the case of ordinary electrolysis without carbon; but the currents are comparable which means higher energy spent to produce less hydrogen.

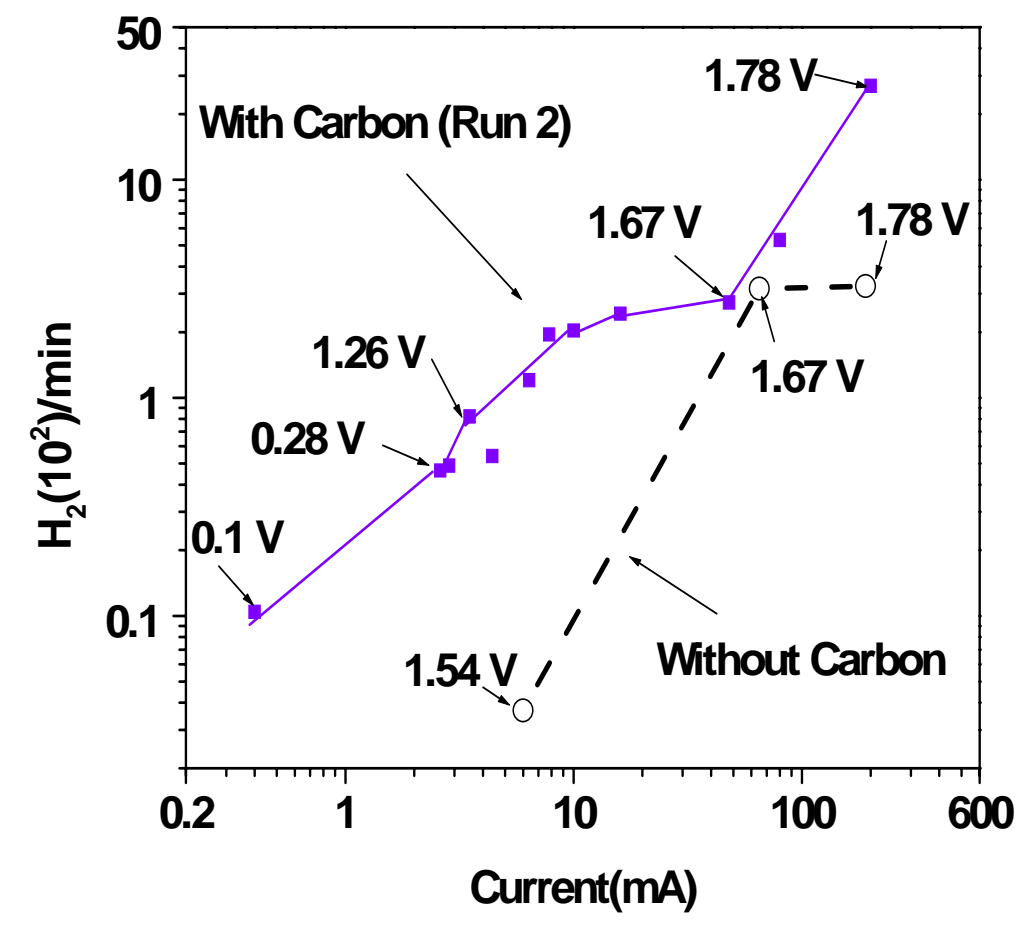

Figure 4-3. $\mathrm{H}_{2}$ produced per minute for run2 is plotted against the current $I_{0}(\mathrm{~mA})$. 


\subsection{Effect of carbon}

In the next plot, a comparison of $A_{H}$ versus different concentrations of carbon at three different $E^{0}$ are made. Two potentials $(1.4 \mathrm{~V}, 1.54 \mathrm{~V})$ above threshold potential for ordinary electrolysis and one below $(0.68 \mathrm{~V})$ were chosen. Although at higher potentials $0.04 \mathrm{~g} / \mathrm{cm}^{3}$ carbon concentration shows a peak, at lower voltages where kinetics need to be improved the concentration of $0.08 \mathrm{~g} / \mathrm{cm}^{3}$ of carbon can be considered to work better.

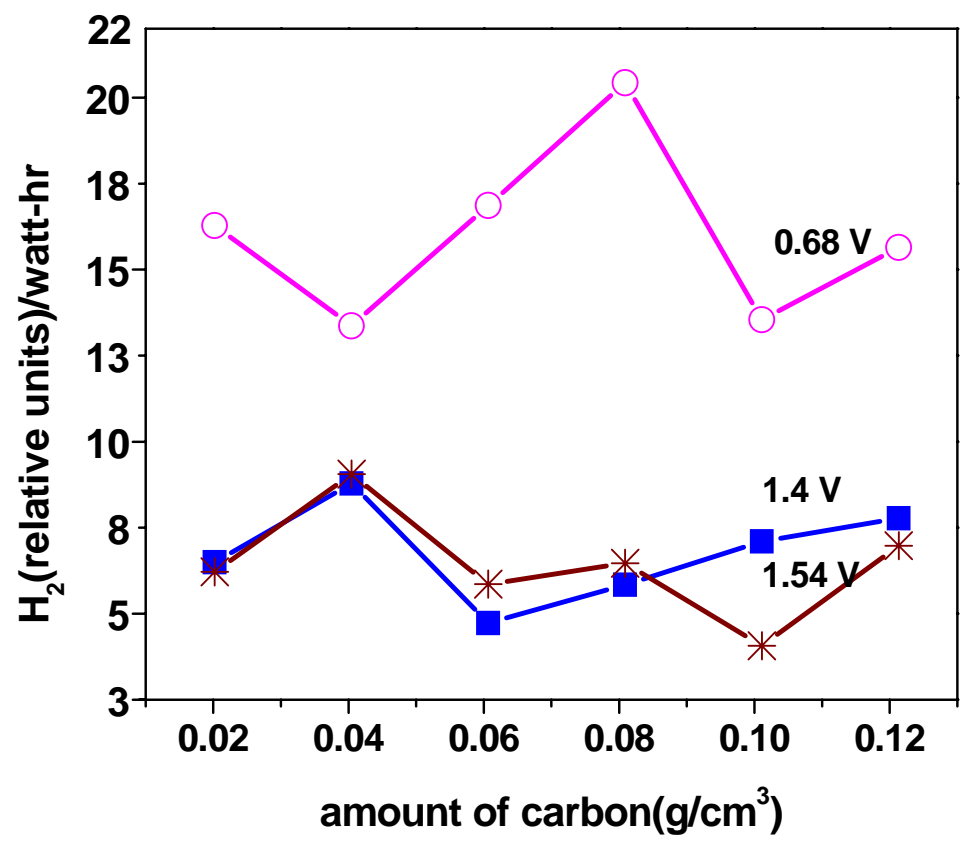

Figure 4-4.Variation of the quantity $A_{H}\left(\mathrm{H}_{2}\right.$ produced per $\mathrm{W}$-hr) is plotted against the carbon concentration for three operating potentials $E^{0}$.

For this reason, most of the work was carried out with this concentration. The error bars represented on $A_{H}$ are due to uncertainties in $I_{0}$ and $t_{H}$. This plot also shows that the lower operating voltages are more energy efficient and yield higher hydrogen per watt-hr 
compared to the higher voltages. Thus it appears that as long as unreacted carbon is present near the electrode, the reaction is more energy efficient at lower voltages.

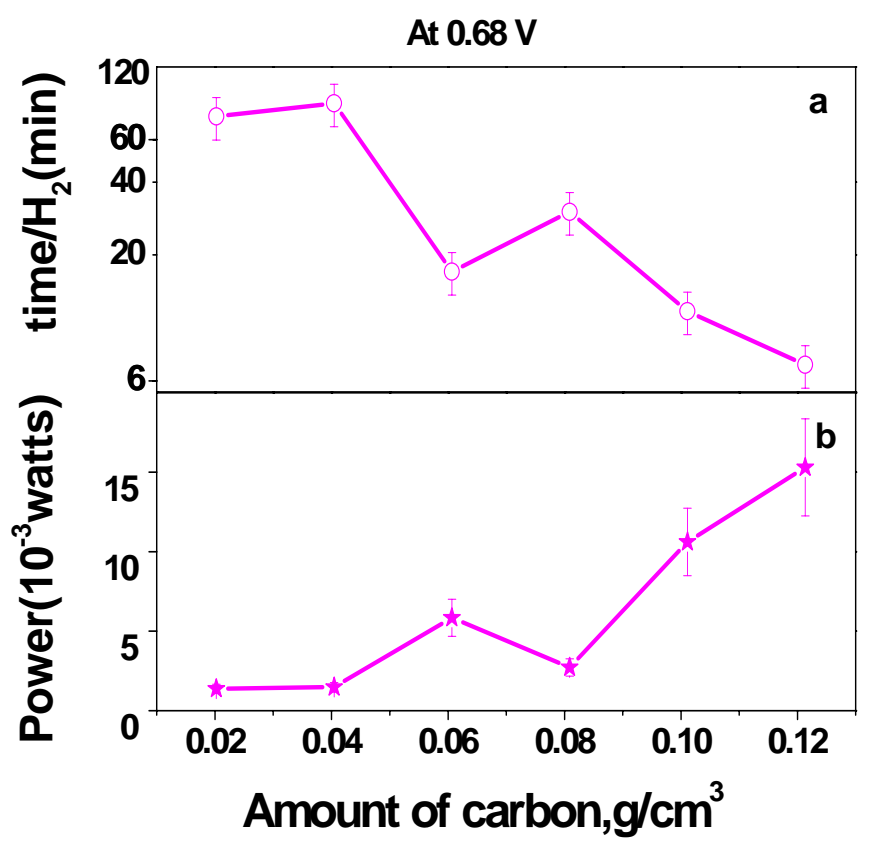

Figure 4-5.Power (watts) and time $t_{H}(\min )$ vs. carbon concentration at $E^{0}=0.68 \mathrm{~V}$

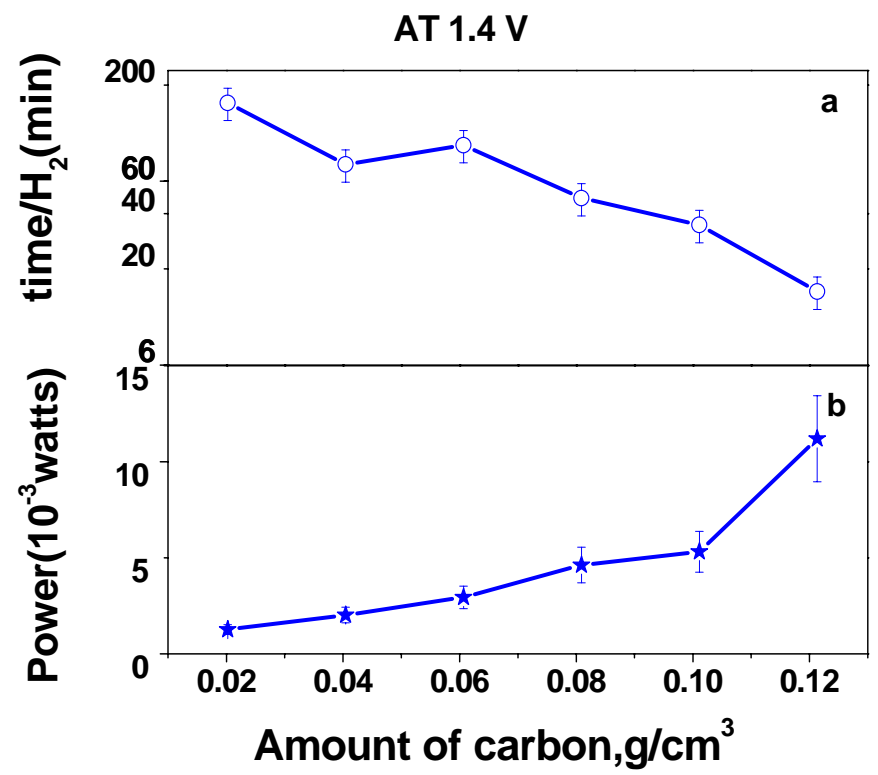

Figure 4-6.Power (watts) and time $t_{H}(\mathrm{~min}) \mathrm{vs.}$ carbon concentration at $E^{0}=1.4 \mathrm{~V}$ 
However this condition is true only to certain point after which saturation occurs and a decrease in amount of hydrogen produced is seen. Also, the parameters power and time $\left(t_{H}\right)$ are compared against the carbon concentration at two different operating potentials. The general trend shows an increase in power with increase in carbon concentration and a decrease in time with increasing carbon concentration. Even though time goes down, the increase in power requirements demand a tradeoff thereby considering $0.08 \mathrm{~g} / \mathrm{cm}^{3}$ as optimum based on the amount of hydrogen produced.

\subsection{Rate of Hydrogen evolution}

The rate of hydrogen evolution which is $1 / t_{H}$ is plotted against various potentials. It can be seen from figure. 16 that for $E^{0}$ values ranging from $0.5 \mathrm{~V}$ to $0.8 \mathrm{~V}$ the evolution rate is comparable to the rapid evolution potentials $\left(E^{0}>1.5 \mathrm{~V}\right)$. This shows that the lower potentials are advantageous to operate with since the evolution rate is almost the same as the energy-consuming higher voltages.

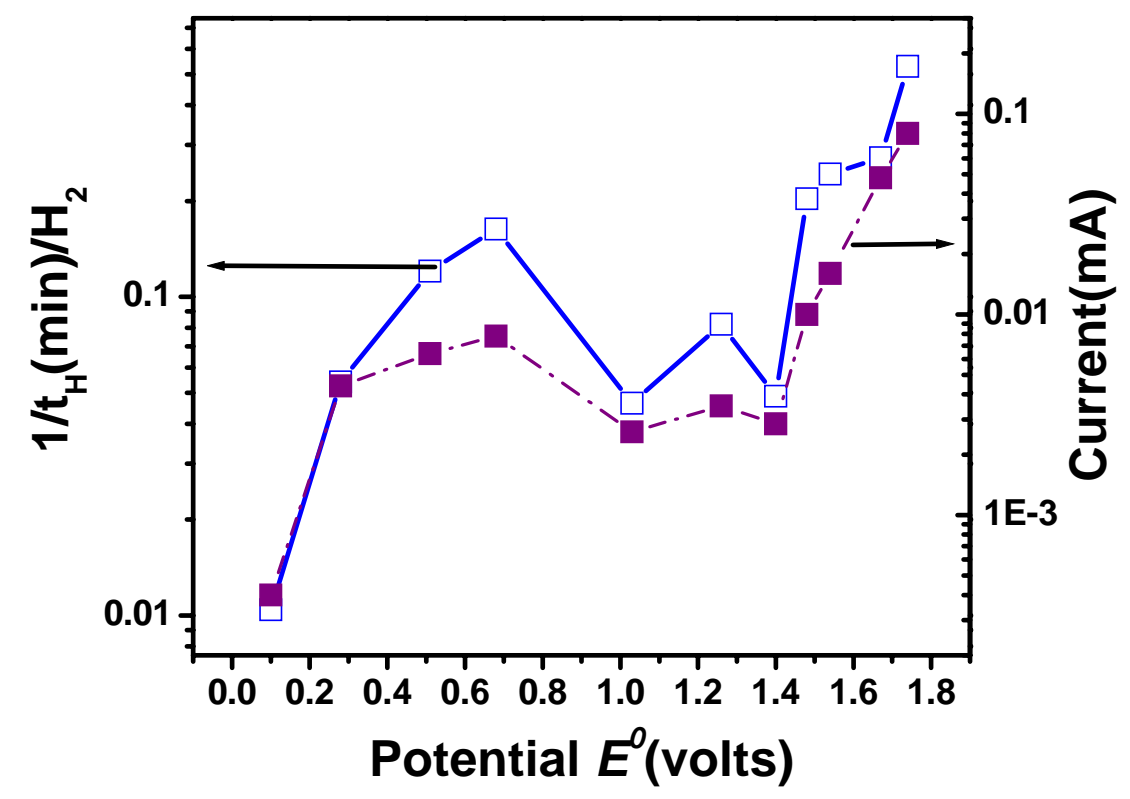

Figure 4-7. Evolution rate $\left(1 / t_{H}\right)$ and current $(\mathrm{mA})$ vs. Potential $\left(E^{0}\right)$ 


\section{CONCLUSIONS AND FUTURE WORK}

\subsection{CONCLUSIONS}

The results presented here have demonstrated that carbon-assisted water electrolysis is an energy efficient technique to produce hydrogen. The hydrogen production in terms of energy efficiency and the amount of hydrogen produced was studied. The various parameters to be considered for energy reduction namely current, time, carbon concentration etc. were measured. A Gas Chromatograph was used to quantify the hydrogen produced at the cathode. From the results discussed in the previous chapter the following conclusions can be drawn.

1) The amount of hydrogen produced per W-hr was found to be higher at lower voltages $\left(E^{0} \simeq 0.2 \mathrm{~V}\right)$. However, since the time taken to produce hydrogen is longer, operating at $E^{0} \simeq 0.5 \mathrm{~V}$ was found to be more practical.

2) The current through the circuit bears an almost linear relationship with hydrogen produced per minute. Also, with increasing potential the current increases thereby increasing the energy consumption.

3) The effect of amount of carbon added to the anode compartment was also investigated by varying the carbon concentration from $0.02 \mathrm{~g} / \mathrm{cm}^{3}$ to $0.12 \mathrm{~g} / \mathrm{cm}^{3}$ of the electrolyte. At lower potentials with $0.08 \mathrm{~g} / \mathrm{cm}^{3}$, the hydrogen produced per W-hr was the highest compared to other carbon concentrations. Although the time taken decreases, the power required increases with increasing carbon concentration. 
4) The evolution rate at lower voltages was almost equal to the evolution rate at higher voltages which indicates a definite increase in activity at lower voltages compared to conventional water electrolysis process.

In summary practical parameters for potential $\left(\left|E^{0}\right| \simeq 0.5 \mathrm{~V}\right)$ and carbon concentration $\left(0.08 \mathrm{~g} / \mathrm{cm}^{3}\right)$ were established after considering various factors. Also since the $\mathrm{CO}_{2}$ produced at the anode is well separated from $\mathrm{H}_{2}$ produced at the cathode, the former can be sequestered using any of the available technique.

\subsection{FUTURE DIRECTIONS}

Even though there is a significant reduction in energy at lower voltages, it may be possible to reduce it further by addition of catalysts to the anode compartment. The presence of catalysts could improve the kinetics as well as reduce the time taken to produce hydrogen. The potential catalysts could be $\mathrm{FeSO}_{4}$, nanocrystalline $\gamma-\mathrm{Fe}_{2} \mathrm{O}_{3}, \mathrm{TiO}_{2}$ with UV light source and $\mathrm{FeCl}_{2}$. The well-known catalytic activity resulting due to $\mathrm{Fe}^{2+} \Longleftrightarrow \mathrm{Fe}^{3+}$ conversion mechanism could be exploited to increase the kinetics. Also carbons with higher surface area $\left(>1000 \mathrm{~m}^{2} / \mathrm{g}\right)$ could be tested for better activity. 


\section{BIBLIOGRAPHY}

1. National Renewable Energy Laboratory. Technology Brief: Analysis of Current-Day Commercial Electrolyzers, Report \# NREL/FS-560-36705, 2004.

2. Coughlin, W. R.; Farooque, M. Electrochemical Gasification of Coal-Simultaneous Production of Hydrogen and Carbon Dioxide by a Single Reaction Involving Coal, Water and Electrons. Ind. Eng. Chem. Process Des. Dev. 1980, 19 (2), 211-219.

3. Coughlin, W. R.; Farooque, M. Consideration of electrodes and electrolytes for electrochemical gasification of coal by anodic oxidation. Journal of Applied Electrochemistry 1980, 10, 729-740.

4. Cox, K. E.; Williamson, K. D. Hydrogen, Its Technology and Implications; CRC press: 1979; Vol. 4.

5. Kermode, R. I. Hydrogen from fossil fuels. In Hydrogen, Its Technology and Implications, CRC press 1979; pp 62-112.

6. Casper, M. S. Hydrogen Production from Fossil Fuels. In Hydrogen Manufacture by Electrolysis, Thermal Decomposition and Unusual Techniques, Park Ridge, N.J. : Noyes Data Corp 1978; pp 15-109.

7. Han, L.; Lim, T. k.; Kim, Y.-J.; Hahm, H. S.; Kim, M. Hydrogen Production by Catalytic Decomposition of Methane over Carbon Nanofibers. Materials Science Forum 2006, 510-511, 30-33.

8. Gasior, S. J.; Forney, A. J.; Field, J. H.; Bienstock, D.; Benson, H. E. Production of Synthesis Gas and Hydrogen by the Steam-Iron Process: Pilot Plant Study of Fluidized and Free Falling Beds. U.S. Dept. of the Interior. Report \# BM-RI-5911 1961. 
9. Johnson, J. L. Continuous steam-iron process US patent\# 3,619,142, 1971.

10. Benson, H. E. Method for the production of a mixture of hydrogen and steam. 3,421,869, US patent\# 1969 .

11. Uchida, H.; Kyogoku, H. Optimizing Hydrogen Production by Steam Reforming Process for Residual Hydrodesulfurization Units. 68th Ann.Meet.American Institute of Chemical Eng, LA USA 1975.

12. Hess, H. V.; Glenham; Guptill, F. E. J.; Fishkill, N. Y. Steam Hydrocarbon Process over Iron-Chromium Catalyst for Synthesis Gas Production. US patent\# 3,485,882 1969.

13. Santos, D. C. R. M.; Lisboa, J. S.; Passos, F. B.; Noronha, F. B. Characterization of Steam Reforming Catalysts. Braz. J. Chem. Eng 2004, 21 (2) pp 203-209.

14. Hydrogen Process Broadens Feedstock Range. Chem. Eng. 1962, 69 (14) pp 88-93.

15. Van der Berg, G. J.; Dammers, W. R.; TeriHaar.L.W Hydrocarbon Gasification Process.In McKeHa J. Advances in Petroleum Chemistry and Refining, Vol.10,Interscience,New York,1965,chap.4 .

16. Konnov, A. A.; Zhu, J.; Bromly, J.; Zhang, D. K. Non-Catalytic Partial Oxidation of Methane over a Wide Temperature Range. Proceedings of the European Combustion Meeting, 2003, Paper \#9, Oct 25-28 Orleans, France.

17. Fickett, A. P.; KalHammer, F. R. Water Electrolysis. In Hydrogen, Its Technology and Implications, CRC Press 1979; pp 4-40.

18. Hoffman, P. Tomorrow's Energy: Hydrogen, FuelCells and the Prospects for a Cleaner Planet; Cambridge:MIT press: 2001. 
19. Konopka, A.; Gregory, D. Hydrogen Production by Electrolysis: Present and Future. 10th Intersociety Energy Conversion Engineering Conference 10th, Newark, Del., August 18-22, 1975, Record. (A75-45920 23-44) New York, Institute of Electrical and Electronics Engineers, Inc., 1975, p. 1184-1193.

20. Kroposki, B.; Levene, J.; Harrison, K.; Sen, P. K.; Novachek, F. Electrolysis: Information and Opportunities for Electric Power Utilities; Report \# NREL/TP-58140605, 2006.

21. Smith, D. H. Industrial Water Electrolysis. In Industrial Electrochemical Processes A.T.Kuhn,Ed, Elsevier Publishing Company 1971, pp. 127-157.

22. Titterington, W. A.; Austin, J. F. Capability of Solid Polymer Electrolyte for Electrolytic Hydrogen Generation. Electrochem. Soc. 1974, 233, p 576.

23. Funk, J. E. Thermochemical Water Decomposition. In Hydrogen, Its Technology and Implications, CRC Press 1979; pp 45-56.

24. Escher, W. J. D. A Preliminary Systems-engineering Study of an Advanced Nuclear Electrolytic Hydrogen Production Facility; ID 8962; 75.

25. Darrow, K.; Biederman, N.; Konopka, A. Commodity Hydrogen from Off-Peak Electricity. In World Hydrogen Energy Conf proceedings, 1st, Miami Beach, Fla, vol.3, 1976, p. $8 \mathrm{C}-17$ to $8 \mathrm{C}-45$.

26. Biederman, N.; Darrow, K. J.; Konopka, A. Utilization of Off-Peak Power to Produce Industrial Hydrogen; Report \# EPRI 320-I; 75.

27. Chao, R. E. Thermochemical Water Decomposition Process. Industrial and Engineering Chemistry Product Research and Development 1974, 13 (2), 94-101. 
28. Funk, J. E. Thermochemical Production of Hydrogen via Multistage Water Splitting Process. Int. J. Hydrogen Energy 1976, 1 (1).

29. Funk, J. E.; Reinstorm, R. M. Energy Requirements in the Production of Hydrogen from Water. Ind. Eng. Chem. Process Des. Dev. 1966, 5 (3), 336-342.

30. Abraham, B. M.; Schreiner, F. General Principles Underlying Chemical Cycles which Thermally Decompose Water. Ind. Eng. Chem. Fundam. 1974, 13 (4), 305.

31. Bamberger, C. E.; Richardson, D. M. Hydrogen Production from Water by Thermochemical Cycles. Cyogenics 1976, 197 (6).

32. Sink, C.; Taylor, A. Nuclear Based Hydrogen R \& D. 2006 DOE Hydrogen Program Merit Review and Peer Evaluation Meeting, 2006.

33. Steinfield, A.; Palumbo, R. Solar Thermochemical Process Technology. Encyclopedia of Physics Science \& Technology 2001, 15, 237-256.

34. Raissi, A. T. Analysis of Solar Thermochemical Water-Splitting Cycles for Hydrogen Production. Hydrogen, fuel cells and infrastructure technologies, FY 2003 Progress report.

35. Development of Solar-powered Thermochemical Production of Hydrogen from Water. Al Weimer for the Solar Thermochemical Hydrogen (STCH) Team. Project ID PD10 2006.

36. Demirbas, A.; Ozturk, T.; Demirbas, M. F. Recovery of Energy and Chemicals from Carbonaceous Materials. Energy Sources, Part A: Recovery, Utilization, and Environmental Effects 2007, 28 (16), 1473-1482.

37. Lin, Y. S. Microporous and Dense Inorganic Membranes: Current Status and Prospective. Separation and Purification Technology 2001, 25 (39). 
38. Reiji, M. W.; Keurentjes, J. T. F.; Hartmans, S. Membrane Bio-reactors for Waste Gas Treatment. Journal of Biotechnology 1998, 59 (155).

39. Ni, M.; Leung, D. Y. C.; Leung, M. K. H.; Sumathy, K. An Overview of Hydrogen Production from Biomass. Fuel Processing Technology 2006, 87 (5), 461-472.

40. Olalde, G.; Gauthier, D.; Vialaron, A.; Fulcheri, L. A new solar system for highly efficient thermolysis of water. Academie des Sciences (Paris) 1986, 302 (20), 12191222.

41. Seibert, M.; King, P.; Zhang, L.; Mets, L.; Ghirardi, M. Molecular Engineering of Algal $\mathrm{H}_{2}$ production. Proceedings of the 2002 US.DOE Hydrogen Program Review Report \# NREL/CP 610-32405. 2002.

42. Graetzel, M. Photoelectrochemical Cells. Nature 2001, 414, 332-344.

43. Mor, G. K.; Shankar, K.; Varghese, O. K.; Grimes, K. A. Photoelectrochemical Properties of Titania Nanotubes. J. Mater. Res 2004, 19 (10), 2989-2996.

44. Kapoor, M. P.; Inagaki, S.; Yoshida, H. Novel Zirconium-Titanium Phosphates Mesoporous Materials for Hydrogen Production by Photoinduced Water Splitting. J. Phys. Chem B 2007, 36 (34).

45. Berger, R.; Hawthorne, C.; Scheffknecht, G. Lime Enhanced Gasification of Solids: A Process Offering New Prospects in Fuel Chemistry. The International Freiberg Conference on IGCC \& XtL Technologies, June 16 - 18, 2005, Freiberg/Saxony, Germany; 2005.

46. Baldwin, R. P.; Jones, K. F.; Joseph, J. T.; Wong, J. L. Voltammetry and electrolysis of coal slurries and H-coal liquids. Fuel 1981, 60, 739-743. 
47. Dhooge, P. M.; Stilwell, D. E.; Park, S.-M. Electrochemical Studies of Coal Slurry Oxidation Mechanisms. J. Electrochem. Soc. 1982, 129 (8), 1719-1724.

48. Dhooge, P. M.; Park, S.-M. Electrochemistry of Coal Slurries: FTIR Studies of Electrolysis of Coal. J. Electrochem. Soc. 1983, 130 (7), 1539-1542.

49. Farooque, M.; Coughlin, W. R. Electrochemical Gasification of Coal (Investigation of operating conditions and Variables). Fuel 1979, 58, pp705-712.

50. Squires, A. M. Clean Fuels from Coal Gasification. Science 1974, 184, pp. 340 - 346.

51. Coughlin, W. R.; Farooque, M. Hydrogen Production from Coal, Water and Electrons. Nature 1979, 279, 301-303.

52. Dworak, R.; Feess, H.; Wendt, H. How to Process Electrolysis with Two-Phase Electrolytes. AIChE Symposium on Electro-organic Synthesis Series 185,75,1978 (38).

53. Coughlin, W. R. Carbon as Adsorbent and Catalyst. I \& EC Product Research and Development 1969, 8 (1).

54. Brinkmann,G. Catalytic effects of activated charcoal (orig. German), Kolloid Z, 123(116)1951 pp 277-287.

55. Seehra, M. S.; Ranganathan, S.; Manivannan, A. Carbon-assisted water electrolysis: An energy-efficient process to produce pure $\mathrm{H}_{2}$ at room temperature. Applied Physics Letters 2007, 90(4).

56. Cox, K. E.; Williamson, K. D. Hydrogen Production by Electrolysis. In Hydrogen, Its Technology and Implications, CRC Press: 1979; pp 111-207. 
57. Mandin, P.; Roustan, H.; Hamburger, J.; Wuthrich, R.; Picard, G. Electrochemical process modeling: water electrolysis for hydrogen production. CHISA 2006: 17th International Congress of Chemical and Process Engineering.

58. Cheng, H.; Scott, K.; Ramshaw, C. Intensification of Water Electrolysis in a Centrifugal Field. J. Electrochem. Soc. 2002, 149 (11), D172-D177.

59. Grob, R. L.; Barry, E. F. Modern Practice of Gas Chromatography; 4th ed. WileyInterscience: 2004.

60. SRI instruments documentation Multiple Gas Analyzer \#2; 2005.

61. SRI instruments documentation. Thermal Conductivity Detector. 2005. 